index ocomunicación | no 10(3) 2020 | Páginas 23-72

E-ISSN: 2174-1859 | ISSN: 2444-3239 | Depósito Legal: M-19965-2015

Recibido el 15_06_2020 | Aceptado el 02_07_2020 | Publicado el 12_11_2020

\title{
NOCIÓN DE VERDAD \\ EN LOS DISCURSOS MEDIÁTICOS \\ Y DIGITALES ANTE LOS DESAFÍOS \\ PARA LA COMUNICACIÓN \\ EN DEMOCRACIA
}

\author{
NOTION OF TRUTH IN MEDIA AND DIGITAL \\ SPEECHES TO THE CHALLENGES \\ FOR COMMUNICATION IN DEMOCRACY
}

https://doi.org/10.33732/ixc/10/03Nocion

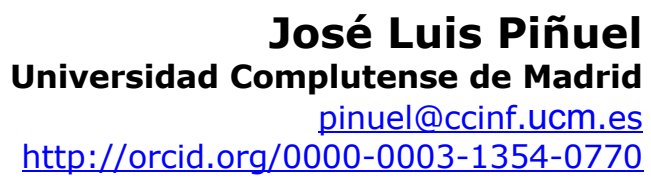

Conferencia impartida en el XVII Encuentro Latinoamericano de Facultades de Comunicación Social FELAFACS 2019 Sucre-Bolivia

25, 26 y 27 de septiembre de 2019, Sucre, Bolivia. 
Resumen: Con esta exposición quiero compartir aquellos conocimientos, experiencias y deseos que he adquirido tras una larga vida de profesor de Teoría y Metodología de la Investigación en Comunicación en la Universidad Complutense de Madrid. Conocimientos, ofrecidos por 40 años de docente y de investigador en Comunicación. Experiencias, vividas gracias al acercamiento y con frecuencia el ejercicio de periodista y editor. Deseos, finalmente, fomentados desde mi condición de ciudadano comprometido como militante de base en partidos de izquierda durante un periodo durante el cual España sale de una dictadura e instaura una sólida democracia. Y sobre conocimientos académicos, (1. El rol de la academia frente a las nociones de verdad), experiencias profesionales (2. El periodismo y la posverdad) y deseos ciudadanos (3. Nuevos sistemas de Comunicación en el Estado de Derecho) giran precisamente los ejes temáticos de este texto.

Palabras clave: periodismo; verdad; posverdad; democracia; información.

\begin{abstract}
With this conference I want to share those knowledge, experiences and desires that, after a long life of Professor of Theory and methodology of Communication research at the Complutense University of Madrid. Knowledge offered by 40 years of teacher and researcher in Communication. Experiences lived thanks to the approach and often the exercise of journalist and editor. Desires, finally, fostered from my status as a committed citizen as a base militant in left-wing parties during a period during which Spain leaves a dictatorship and establishes a solid democracy. And about academic knowledge, (1. The role of the academy against the notions of truth), professional experiences (2. Journalism and post-truth) and citizen desires (3. New Communication systems in the Rule of Law) revolve precisely the thematic axes of this CONGRESS. I assume then the development of these axes to articulate my speech.
\end{abstract}

Keywords: Journalism; Truth; Post-Truth; Democracy; Information. 


\section{EI rol de la academia frente a las nociones de verdad}

El término ACADEMIA identifica a las diversas instituciones culturales o educativas establecidas y con autoridad pública para el desempeño docente de carácter científico, profesional, artístico, técnico, o simplemente práctico, capaz de garantizar la producción y la reproducción del saber hacer y el hacer saber por parte de sus componentes, los académicos, cuyo trabajo radica en espacios institucionales que también reciben el nombre de ACADEMIA. Y a la ACADEMIA, a lo largo de toda la trayectoria histórica de la cultura occidental, le ha competido el establecer la calidad del saber hacer y del hacer saber socialmente relevantes, y de hacer el seguimiento de la formación de los profesionales especializados en la producción de los saberes.

Este congreso se enmarca así dentro de esta trayectoria histórica y nuestro ámbito dentro de la ACADEMIA cubre el objetivo de establecer y hacer el seguimiento de la calidad del saber hacer y del hacer saber propio de los DISCURSOS MEDIÁTICOS Y DIGITALES según las NOCIONES DE VERDAD que mejor sirvan a los DESAFÍOS PARA LA COMUNICACIÓN EN DEMOCRACIA. Un objetivo como este es gravemente vulnerable ante los cambios históricos a que se tienen que enfrentar los profesionales que actúan en las nuevas plataformas y que por ello requieren de nuevos abordajes teóricos y metodológicos en tiempos de mediaciones digitales. Mi intención en esta exposición es ofrecer mi reflexión a propósito de las repercusiones sociales de la tecnología que posibilita la circulación digital (o numérica, como dicen los franceses) de las señales, los mensajes, los textos y los discursos que sirven a las interacciones sociales de las cuales depende la participación ciudadana en las democracias, y ello se encuadra necesariamente dentro de los enfoques o perspectivas epistemológicas y éticas en torno al conocimiento que en el siglo XXI se califica como cibercultura y que deben ser cuestionados ante las infecciones que intoxican los flujos periodísticos, generando esos globos herméticos y aislados del entorno, llamados por ello burbujas informativas. A cada uno de estos aspectos dedicaré un apartado.

\subsection{Formación de profesionales en las nuevas plataformas}

Las tesis doctorales y los proyectos competitivos de investigación y desarrollo a nivel estatal son dos clases de documentos que representan dos momentos (muy importantes) de la producción académica. Las primeras se corresponden con el culmen del máximo nivel que se puede aspirar en la titulación universitaria, indispensable para iniciar una carrera académica, en tanto que los segundos son la expresión de la excelencia investigadora que el Estado, a través del Ministerio correspondiente (ya sea, Ciencia e Innovación o Economía, Industria 
y Competitividad) concede mediante una financiación temporal acorde con unos requisitos muy estrictos y una evaluación muy rigurosa. Pues bien, en España tuve oportunidad de analizar muy exhaustivamente esta producción académica haciendo un sondeo que cubrió la etapa 2013/2016, y que se está continuando en una segunda etapa hasta 2020, en la confianza que este seguimiento será prolongado ${ }^{1}$. Sírvanos de ejemplo para mostrar nuestra reflexión a este propósito.

Nos preguntamos ¿cuál es la intención dominante de los Proyectos I+D y de la Tesis doctorales cuyo objeto de estudio son las prácticas sociales de Comunicación? ¿qué metas se persiguen? Se cuestionaron cuatro tipos de finalidades. La primera y más básica consiste en las descripciones, es decir, una meta orientada a describir registrando, clasificando, catalogando, presentando y/o elaborando datos sobre prácticas de comunicación, como por ejemplo medir audiencias, inversiones, posibles efectos, etc. La segunda finalidad tiene que ver con las explicaciones, esto es, explicar relaciones entre los datos que hayan sido recabados o elaborados y exponer modelos o esquemas para anticipar la evolución del objeto de estudio, recurriendo a teorías conocidas para demostrar, rebatir, actualizar o proponer una nueva perspectiva teórica. La tercera finalidad se relaciona con las valoraciones, es decir, evaluar, contrastar o validar modelos teóricos y/o metodológicos para refutarlos o confirmarlos como por ejemplo el modelo de disonancias cognitivas en los cambios de actitudes, o evaluar la teoría de marcos cognitivos al analizar el framing en los discursos machistas. Por último, la cuarta finalidad de las investigaciones tiene que ver con las intervenciones, esto es, intervenir en prácticas comunicativas en curso para optimizar efectos, como por ejemplo cambiar conductas, incrementar la creatividad o influir en los procesos sociales. En el Gráfico 1 se muestra a este respecto que los principales y más característicos objetivos de las investigaciones en Comunicación en España tienen que ver con estudios descriptivos que buscan registrar, clasificar o catalogar datos sobre prácticas comunicativas y, en particular, sobre actividades que desarrollan los medios de comunicación de masas tanto convencionales como en línea.

1 Ver www.mapcom.es. 


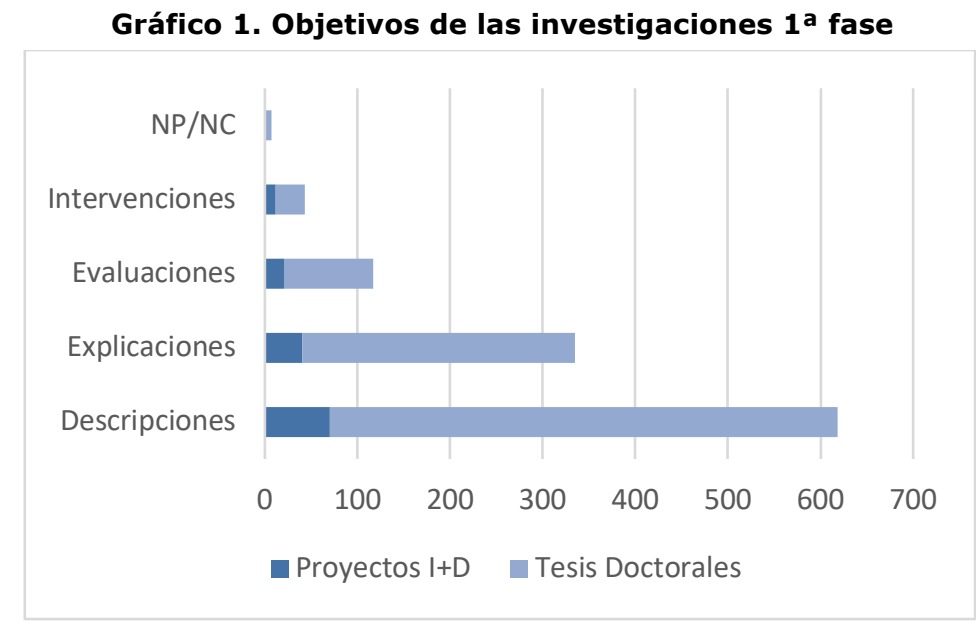

Fuente: MapCom.

Esta clase de metas, que buscan pormenorizar el funcionamiento de la comunicación mediática, brindan sesgos de identidad tanto a la investigación como a los investigadores de comunicación en España, pues parecería que no se puede aspirar a plantear otra clase de objetivos. Describir es un primer paso por cumplir en cualquier proceso de investigación en comunicación, por lo tanto, la posible crítica solo vendría por limitarse a describir recopilando datos sin explicarlos, sin evaluar los modelos propuestos para explicarlos y sin llegar a proponer intervenciones de cambio. Más aún, los principales objetos de estudio de las investigaciones en comunicación están relacionados con la comunicación mediática, en particular con los medios de comunicación convencionales, pero no en el soporte online. En el Gráfico 2 se puede apreciar que la comunicación mediática, tanto en Proyectos I+D como en Tesis doctorales, es el objeto privilegiado y más frecuente, frente a otros objetos de estudio entre las comunidades científicas, ya sea comunicación organizacional, grupal o interpersonal. 
Gráfico 2. Objetivos generales de estudio de las investigaciones en Comunicación en España

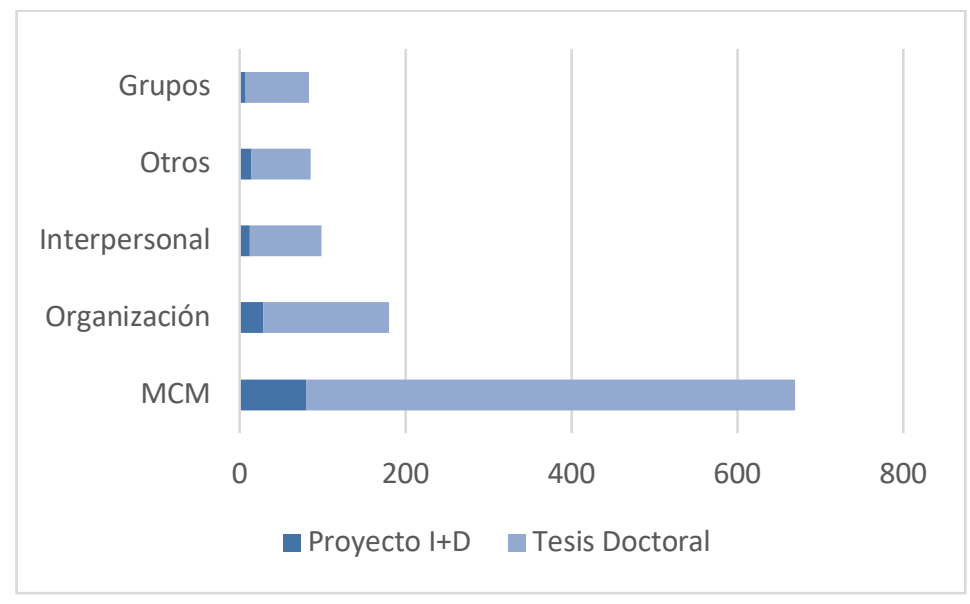

Fuente: MapCom.

Y en la era de Internet, en la que están cambiando los modos de nuestras relaciones sociales e individuales, y en la que también se modifican las formas de comunicarse y de acceder a las fuentes mediáticas, cabría suponer que los investigadores españoles centrasen sus intereses por estudiar las distintas facetas de la comunicación online; sin embargo, no es así (ver Gráfico 3) porque destacan, y por mucho, - cuatro veces más-, los objetos de estudio convencionales frente a los virtuales.

Gráfico 3. Objetivos de estudio offline vs. online

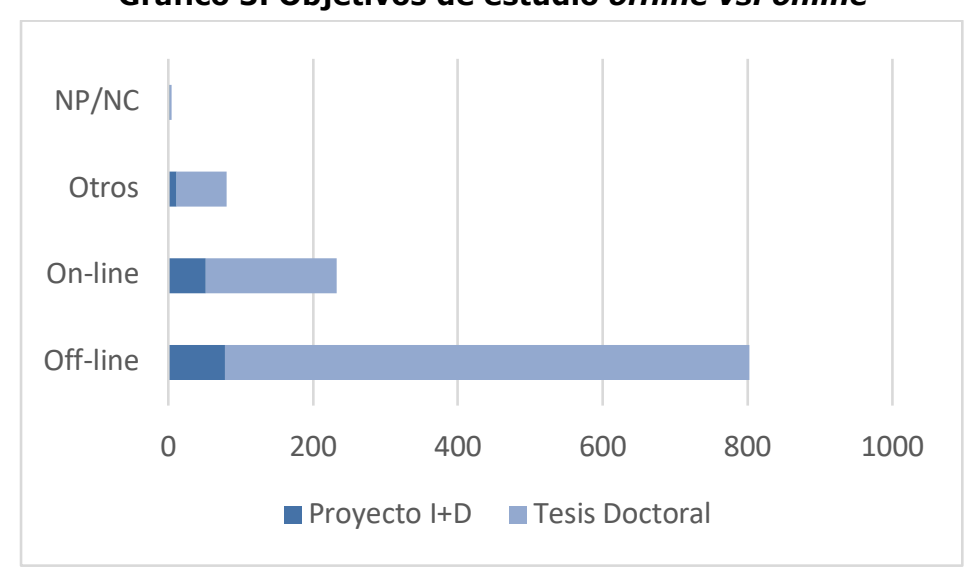

Fuente: MapCom. 
Cabe esperar que, en un futuro cercano, los investigadores reviertan las formas de construir sus objetos de estudio para priorizar la comunicación online sobre la comunicación offline. En la investigación MapCom citada, no obstante, el principal objeto de estudio - de los investigadores seniors y de los doctorandos- se construye en torno a los medios de comunicación convencionales; concretamente, por cada investigación que analiza un medio online, hay cuatro investigaciones dedicadas a los medios convencionales. En el caso de los Proyectos I+D esta proporción es de 1 a 2 en tanto que en las Tesis doctorales es de 1 a 5 . Así era hasta hace dos años. A ver qué resultados a este propósito nos depara MapCom de la $2^{\underline{a}}$ fase.

\subsection{Nuevos abordajes teóricos y metodológicos en tiempos de mediaciones digitales}

El trayecto histórico de las tecnologías de la comunicación ha sido trazado siempre en función de los recursos materiales empleados para conseguir interacciones sociales basadas en la circulación de expresiones. Y hasta haber llegado a la tecnología que hoy posibilita la circulación digital (o numérica, como dicen los franceses), las expresiones requieren originariamente transmisión de señales física y sensorialmente procesables; de cómo sean procesados secundariamente los flujos de señales depende la codificación y decodificación de los mensajes; la codificación y decodificación humana de mensajes se opera recurriendo a lenguas naturales, a diferencia del recurso al uso de algoritmos como hacen los programas informáticos; pero para recurrir a las lenguas naturales, es imprescindible haber adquirido la competencia lingüística que, sin embargo, no es sólo haber aprendido a usar reglas gramaticales, sino también regulaciones sociales; podría decirse que del uso de reglas gramaticales se deriva la codificación y decodificación de textos con sus significados, pero por la aplicación de regulaciones sociales los textos se sitúan en contextos que, si son reconocibles por los interlocutores, dotan de sentidos a las significaciones y es entonces cuando aparecen los discursos que hacen posibles las interacciones comunicativas.

Conviene advertir que no toda circulación de expresiones reproduce interacciones comunicativas. Por ejemplo, un operador en el transporte de señales digitales, un repartidor de correo, un transportista de libros, etc., prestan servicio a esa circulación de expresiones (mensajes electrónicos, cartas, volúmenes impresos, etc.), pero no usan tales configuraciones de las expresiones material y formalmente articuladas por flujos de señales, codificación de mensajes, reproducción lingüística de textos socialmente contextualizados, etc.participando en la interacción social que los interlocutores establecen por ese intercambio al que ellos contribuyen prestando un servicio remunerado. Ahora bien, no es posible interacción comunicativa alguna sin un intercambio de 
expresiones adecuadamente regulado por códigos de significación compartidos y más o menos satisfactoriamente usados conforme a objetivos que los interlocutores persiguen de forma más o menos transparente. 0 , dicho de otra forma, si hay comunicación hay interacción social - ya sea anticipada, ejecutada, o por consecuencia-, pero no toda interacción social es comunicación, sino sólo aquella que para ser ejecutada requiere del intercambio de expresiones discursivas adecuadamente regulado por códigos de significación compartidos y más o menos satisfactoriamente usados al tratar las expresiones.

Si hay pues intercambio comunicativo de expresiones, es porque existe también la interacción social que se ejecuta, la que precede condicionando su desarrollo, y también la que es consiguiente al desarrollo de los objetivos pretendidos con la comunicación. Pero si hay comunicación, hay también una actividad cognitiva desarrollada según las destrezas y registros de la experiencia de apropiación del entorno por parte de los sujetos en el manejo de códigos, sin la cual aquella interacción fracasará. Por todo esto conviene reiterar el juego de mediaciones, $\mathrm{o}$, dicho de otra manera, de condiciones y variables que confluyen en las interacciones comunicativas desde la original disponibilidad de señales, hasta la puesta en escena de los discursos sin los cuales una determinada interacción social es imposible.

DISCURSO es una de las voces léxicas con mayor número de acepciones. La vigesimotercera edición del Diccionario de la RAE, edición conmemorativa de su Tricentenario, recoge 12 acepciones, y el Nuevo tesoro lexicográfico de la lengua española (NTLLE) recoge hasta 47 lemas que constituyen el conjunto de aportaciones lexicográficas distintas del término DISCURSO en los diccionarios de la lengua aparecidos desde 1604, como el Diccionario muy copioso de la lengua española y francesa, de Jean Palet, editado en París por Mathieu Guillemot, ese mismo año. Cuando se efectúa hoy la búsqueda del término en la consulta de la $\mathrm{RAE}^{2}$ puede advertirse que en todas las acepciones hay una imagen implícita de flujo no aleatorio, sino articulado, de expresiones y representaciones mentales asociadas. Sin embargo, en ninguna de estas acepciones aparecen los términos que acabamos de traer a colación, como flujo, expresiones y representaciones mentales. Sólo aparece el término articulado referido a lenguaje en acción, según la acepción no 10, que reza: «10. m. Ling. Lenguaje en acción, especialmente el articulado en unidades textuales. La lingüística del discurso» (Diccionario de la RAE) y remitido a un supuesto, pero no dicho, flujo de unidades textuales...

${ }^{2}$ https://dle.rae.es/?id=DtpVc7a. 
En definitiva, tanto si se repara en los usos léxicos del término discurso, como si se examinan sus definiciones en la abundante literatura científica que lo debate, es incuestionable que no puede haber discurso alguno sin que exista comunicación (o circulación de expresiones), conocimiento compartido, e interacción social ya sea antes, durante, o después de aquello a lo que denominar propiamente discurso. Parafraseando a Van Dijk, T. (2005), una Teoría del discurso es incompleta si no se vincula con la Teoría del conocimiento, o si no es capaz de establecer relaciones entre discurso y representaciones sociales.

Se entiende por REPRESENTACIÓN aquel producto de la actividad cognitiva de los sujetos en virtud del cual éstos controlan consciente o inconscientemente sus reacciones conductuales distanciándose temporalmente de los estímulos presentes del entorno, al recordar y/o anticipar otros estímulos no presentes para mejorar sus respuestas. La elaboración de representaciones se presupone en la conducta de todos aquellos seres vivos dotados de capacidad de aprendizaje y no se presupone en aquellas conductas que los seres vivos ponen en juego por efecto de patrones de respuesta adquiridos genéticamente o heredados. En la especie humana, el aprendizaje y el lenguaje facilita el que las representaciones sean expresables por los sujetos y colectivamente compartidas, y es la expresión de las representaciones la que produce trayectos más largos y complejos para las correspondencias compartidas entre categorías del entorno cada vez más ricas y categorías de acción de los sujetos, cada vez más complicadas y generalizadas.

En consecuencia, la convergencia de mediaciones que intervienen cuando dos o más sujetos desarrollan una interacción social poniendo en juego el capital cognitivo necesario para comunicarse haciendo uso de señales, mensajes, textos y discursos, no debe ser ignorada, pero si el procesamiento de las señales es numérico o digital (de dígito o número) su dominio está restringido al funcionamiento de los artefactos que se emplean para su transmisión, cuya tecnología reduce casi a cero las distancias en el tiempo y el espacio. Ahora bien, se incrementa con ello la dependencia que social, económica y culturalmente se impone para la disponibilidad y el manejo de la tecnología informática para el tratamiento de los mensajes, mientras que para la circulación de textos contextualizados, la competencia lingüística y social puesta en juego en los discursos, mediatiza la interacción social lograda por la comunicación, y ésta se transforma y reproduce no por efecto de la mediación digital, sino por efecto de los nuevos contextos sociales y cognitivos que la tecnología de las trasmisiones impone. Y esto plantea el problema de cómo desarrollar la alfabetización digitaly, para el caso de las comunicaciones mediáticas, la News Literacy o alfabetismo informativo de las noticias de la actualidad. 


\subsection{Alfabetización digital y News Literacy}

Alfabetización es adquirir la destreza de saber leer y escribir. El origen de este término está en la expansión del alfabeto entre los pueblos que fueron adoptándolo y adaptándolo mediante la enseñanza y el aprendizaje de una nueva destreza cognitiva: las grafías se quedaron sin significado y adquirieron su relevancia como simples trazos para representar, mediante sus combinaciones, sonidos silábicos, los cuales obtienen la nueva complejidad de ser representados por grafías compuestas de letras vocales y/o letras consonantes. El reducido número de letras y el abundante, pero limitado, número de combinaciones para representar las sílabas de las palabras habladas, exigía a su vez un previo dominio del repertorio gráfico de las letras, sólo posible de ser adquirido mediante su memorización: la retención y evocación de sus grafías correspondientes necesitaba también acompañarse de la habilidad para trazarlas, de la habilidad para reconocerlas, pero también de la habilidad previa para repertoriarlas dándoles un nombre. Así, por ejemplo, los nombres de las letras griegas (alpha, beta, gamma, etc.), —en realidad un préstamo del fenicio y que dieron lugar al término de alfabeto-, fueron simplemente un sonsonete diseñado para memorizar los nombres de las letras, utilizando lo que se denomina principio acrofónico, en una serie retenida mediante evocación mecánica en la mente del sujeto. Un auténtico alfabeto, la única base de la futura alfabetización, sólo podía resultar operativo cuando sus elementos, despojados de cualquier significado independiente, fuesen manejados mecánicamente a partir primero de su aprendizaje mnemotécnico, y, segundo, de las destrezas y de las habilidades para trazarlos y reconocerlos conforme al proceso complejo de codificación y decodificación expresivas.

Por consiguiente, la invención del alfabeto impone socialmente por primera vez una división del trabajo para el que se especializan los escribas, hasta que el proceso de alfabetización extiende la enseñanza y aprendizaje de la lectura y la escritura a una parte de los ciudadanos como base de su educación cívica. Los griegos, pues, no sólo inventaron un alfabeto: inventaron la alfabetización. Sin embargo, la alfabetización experimentó un retraso temporal: no fue afrontada en Grecia quizá hasta trescientos años después de que se resolviera el problema tecnológico de su implantación como base de la educación cívica, dejando obsoleto el rol profesional del escriba o el escribano, y suprimiendo su prestigio elitista característico de las épocas anteriores, aunque la alfabetización casi fue abandonada durante un largo periodo en la Europa posterior a la caída de Roma.

A lo largo de la Edad Media y hasta la aparición y extensión de la imprenta de Gutenberg, los cambios en las destrezas adquiridas por la alfabetización iban unidos al empleo de los trazos de la escritura manual, de cuyas copias se seguía 
la evolución gráfica de las letras, la evolución ortográfica de los textos, y la transformación ritual de sus contextos asociados a la actividad intelectual, mayoritariamente restringida a los entornos eclesiásticos de los monasterios, escuelas catedralicias y universidades medievales. Posteriormente, con la extensión de la imprenta y su tecnología de edición sirviéndose de los tipos móviles, las destrezas propias de la alfabetización quedan progresivamente vinculadas a los cambios introducidos por la producción industrial de textos, cuyo mercado se implanta y crece aceleradamente fuera de los entornos eclesiásticos, multiplicándose la población de lectores, pero sobre todo generándose nuevos contextos sociales que secularizan la escritura y la lectura, dando lugar a una eclosión tal en la diversidad de discursos, tanto religiosos (Reforma y Contrareforma), como científicos (la Enciclopedia y las Academias de Ciencias), como literarios y artísticos (los relatos, la novela, el teatro, la ópera...), como sociales (el periodismo de las gacetas, y la publicidad), que por ellos se llega a la Revolución Francesa y a la aparición de la nueva clase social de la burguesía y su extensión a todo Occidente.

Finalmente, en la segunda mitad del siglo $\mathrm{xx}, \mathrm{y}$ tras las trasformaciones técnicas en la transmisión analógica de señales electrónicas - primero el telégrafo y el teléfono, luego la radio y posteriormente la TV - aparece el cambio del procesamiento numérico o digital en el tratamiento y trasmisión de señales cuyo control informacional es facilitado por aparatos cada vez más sofisticados, pero, sin embargo, cada vez más accesibles al uso doméstico y personal en entornos privados e incluso íntimos, gracias a la instalación industrial de compañías multinacionales especializadas en el tratamiento y trasmisión de las señales ajustadas a la circulación masiva y bidireccional de mensajes cuya configuración textual es indistintamente acústica, audiovisual o escrita, pero de contexto abierto, es decir, sin circular por entornos limitados por ritual alguno de interacción social. El único entorno de interacción remite al ámbito de la identidad de los interlocutores que, por el único motivo de estar conectados en red, adquieren una supuesta legitimidad para expresarse, pero sin poder asegurarse de lograr objetivos concretos en su interacción. Su interacción es su expresión puesta en circulación, salvo cuando del control de esta circulación se siguen intercambios concretos de otra naturaleza en el exterior de las redes digitales: v.g. mercancías y dinero en el comercio electrónico, datos en el servicio de noticias, o emoción en la contemplación artística, etc. Por ello, se torna necesaria la supuesta alfabetización digital, que consiste en adquirir las habilidades indispensables para cuestionarse los vínculos entre las interacciones sociales que se persiguen y el valor de los discursos. Valor de verdad para el conocimiento, pero también valor de bien para la convivencia social, y valor de 
belleza para el placer estético. Se llega así al planteamiento de cuáles son las perspectivas epistemológicas y éticas en torno al conocimiento en el siglo XXI, que hay que adoptar.

\subsection{Perspectivas epistemológicas y éticas en torno al conocimiento en el siglo XXI}

Al cuestionarse los vínculos entre las interacciones sociales que se persiguen y el valor de los discursos, aparecen valores diferentes de discursos según prime en ellos la credibilidad o confianza para representar válidamente la realidad; o bien para representar lo bueno; o bien para compartir emotivamente representaciones por medio de la expresión. No obstante, aunque prime cuestionarse en los discursos su racionalidad para representar la verdad, eso no evita cuestionarse el bien ni las emociones compartidas por medio de la expresión. Pero también, aunque prime cuestionarse en los discursos su eticidad para representar el bien, eso no evita cuestionarse la verdad ni las actitudes compartidas sirviéndose de la expresión. Incluso, aunque prime cuestionarse en los discursos su estética para representar la expresión, eso no evita cuestionarse lo bueno ni las referencias compartidas a propósito de la realidad.

En el Cuadro 1, se ilustran mediante flechas los acuerdos para encuadrar (framing) la prelación del sentido de los discursos según los dominios de existencia del acontecer que se representa en ellos. Así, si tomamos en consideración, en primer lugar, un dominio de existencia propio de una situación REAL -algo que acontece, o se disponen los medios para que acontezca- la dirección de la flecha que apunta hacia los formatos de discurso propios del Derecho y la Política significa que la ESTÉTICA y la RACIONALIDAD se subordinarían a la ÉTICA. En la misma situación REAL, en los formatos de discurso propios del Espectáculo y de las Artes plásticas, la ÉTICA y la RACIONALIDAD se subordinarían a la ESTÉTICA. Y, finalmente, en esta misma situación de realidad, en los formatos de discurso propios de la Ciencia, la ÉTICA y ESTÉTICA se subordinarían a la RACIONALIDAD.

En segundo lugar, si fijamos la atención en una situación CREIBLE -no hay acontecer, aunque pudiera acontecer o se tiene fe de su acontecer-, la dirección de la flecha que apunta hacia los formatos de discurso moral propios de las Parábolas o de las Fábulas, significa que ESTÉTICA y RACIONALIDAD se subordinarían a la ÉTICA. Mientras que, en los formatos de discurso propios de la Novela, la dirección de la flecha significa que ÉTICA y RACIONALIDAD se subordinarían a la ESTÉTICA.Y, finalmente, en los formatos de discurso propios de los relatos del Mito (o de las creencias), la dirección de la flecha significa que ÉTICA y ESTÉTICA se subordinarían a una RACIONALIDAD. 
Para terminar, en tercer lugar, si fijamos la atención en una situación DESEADA - en la que aún no hay acontecer real, pero se incentiva el deseo de que acontezca-, la dirección de la flecha que apunta hacia los formatos de discurso propios de la Publicidad o de la Propaganda, significa que ESTÉTICA y RACIONALIDAD se subordinarían a la ÉTICA. Mientras que, en los formatos de discurso propios de la Égloga y la Poesía lírica, la dirección de la flecha significa que ÉTICA y RACIONALIDAD se subordinarían a la ESTÉTICA. Y, finalmente, en los formatos de discurso propios de la Filosofía moral, la dirección de la flecha significa que ÉTICA y ESTÉTICA se subordinarían a la RACIONALIDAD.

\section{Cuadro 1. Dominios de existencia en los discursos $y$ acuerdos para encuadrar su sentido}

\begin{tabular}{|c|c|c|c|}
\hline \multicolumn{4}{|c|}{ Acuerdos de SENTIDO sobre los discursos } \\
\hline $\begin{array}{l}\text { DOMINIOS DE } \\
\text { EXISTENCIA }\end{array}$ & $\begin{array}{l}\text { ÉTICA } \\
\text { Bueno//Malo } \\
\text { Permitido//Prohibido } \\
\text { Prescrito//Opcional } \\
\text { Exigido//Libre } \\
\end{array}$ & \begin{tabular}{|l} 
ESTÉTICA \\
Bello//Feo \\
Expresivo//Inexpresivo \\
Brillante//Oscuro \\
Novedoso//Redundante \\
\end{tabular} & $\begin{array}{l}\text { RACIONALIDAD } \\
\text { Verdadero//Falso } \\
\text { Necesario//Contingente } \\
\text { Preciso//Impreciso } \\
\text { Posible//Imposible } \\
\end{array}$ \\
\hline $\begin{array}{l}\text { REAL } \\
\text { (Acontece, o se } \\
\text { disponen los medios } \\
\text { para que acontezca) }\end{array}$ & Derecho, Política...4 & $\begin{array}{l}\text { Espectáculo, } \\
\text { Arte plástica }\end{array}$ & Ciencia \\
\hline $\begin{array}{l}\text { CREIBLE } \\
\text { (No acontece, aunque } \\
\text { pudiera acontecer o } \\
\text { se tiene fe de su } \\
\text { acontecer) }\end{array}$ & Parábola, Fábula $<$ & Novela & Mito \\
\hline $\begin{array}{l}\text { DESEADA } \\
\text { (No acontece, pero se } \\
\text { incentiva el deseo de } \\
\text { que acontezca) }\end{array}$ & $\begin{array}{l}\text { Publicidad, } \\
\text { Propaganda }\end{array}$ & Égloga, Poesía lírica & Filosofía moral \\
\hline
\end{tabular}

Fuente: elaboración propia.

Por ejemplo, solo para el formato libro, y excluyendo otros formatos existentes en la comunicación de masas, el diseño de la maqueta, el de la composición de los textos, el de la cubierta y encuadernación, así como el de los campos semánticos con que los autores y editores titulan las obras, facilitan en conjunto anticipar si se trata de una novela, de poesía, de ciencia, de filosofía, de leyes, de publicidad, de religión, etc., aún antes de leer y decodificar significado alguno en los textos interiores. ¿Puede uno, por el contrario, imaginar la ambigüedad perturbadora que se originaría en la presentación de un texto de Ciencia o de Leyes cuyo formato, incluida la composición tipográfica, fuera el habitual de la 
poesía, del relato literario o el del guion teatral? Los acuerdos sobre las prelaciones del sentido en los discursos se hallarían pues relacionados entre sí por regulaciones de orden o subordinación, que conviene estudiar; la propuesta es comprobar cómo las sanciones sociales, los códigos lingüísticos, y los criterios epistémicos de validez para las referencias, reproducen regulaciones que se manifiestan en los formatos de los discursos, al objeto de facilitar las anticipaciones de sentido, las cuales se van adquiriendo por hábito en el aprendizaje sociocultural de los escenarios de interacción. La llamada cibercultura puede ser considerada un producto de los cambios experimentados por la hibridación de los nuevos patrones de sentido que están transformando la puesta en escena de los discursos cuando se recurre a las mediaciones digitales del tratamiento y transmisión de señales, del control informático de los mensajes y, en consecuencia, de los cambios en la contextualización de los textos y de la puesta en escena de los discursos.

\subsection{Cibercultura}

Aunque el término de cibercultura no se encuentra en el diccionario de la Real Academia Española (RAE), la noción, de todos modos, se utiliza con frecuencia para referirse a la cultura que se desarrolla en el ciberespacio: un entorno artificial que, desarrollado mediante herramientas informáticas, contiene los residuos y registros que deja la circulación de mensajes, a partir de cuyo tratamiento se persigue el control informacional o cibernético de la actividad realizada por los usuarios. Cibernética es un término que remite al estudio de la construcción de sistemas electrónicos y mecánicos a partir de su comparación con los sistemas de comunicación y regulación automática de los seres vivos. Norbert Wiener acuñó este término en su libro Cibernética o el control y comunicación en animales y máquinas, publicado en 1948. La cibercultura comprendería entonces el sistema de control y comunicación que se despliega en el ciberespacio. Y su utopía tecnológica sería recurrir a la inteligencia artificial para procesar los macrodatos (big data) derivados del tejido de las conexiones entre los usuarios examinando la naturaleza de sus discursos, y realizar después una cartografía de ese ciberespacio donde se despliega la cibercultura. Pero entre tanto, cada vez son más porfiados los proyectos orientados a obtener rendimientos de este supuesto, y de forma recurrente se da cuenta de los conflictos surgidos a este propósito: el caso de las noticias falsas (fake news) con ocasión de las campañas electorales como la de Donald Trump, o la del referéndum del Brexit, etc.

Una cosa es cierta en lo que concierne a la cuestión de si existe o no una cibercultura: las compañías que por su implantación universal y su volumen de 
beneficios se sitúan a la cabeza de la economía mundial, ya no son las energéticas, sino las que podríamos llamar cibernéticas (Facebook, Apple, Google, ...). Podría afirmarse que es el triunfo de la información sobre la entropía. Sin embargo, existe un riesgo grave en esta deriva histórica.

Los algoritmos de la inteligencia artificial (AI, del inglés Artificial Intelligence) orientan ineluctablemente sus procesos de aprendizaje a eliminar la duda cuando hay que tomar decisiones, pues de lo contrario no se llegaría a tomar decisión ninguna. Y si esto conduce necesariamente también a eliminar probabilidades de error, se procede a establecer igualmente la imposibilidad del error posible, razón por la cual nunca habrá sentimiento de fracaso y tampoco sentimiento de culpa en la AI: la inconmovible tiranía. En este sentido, entre la inteligencia artificial y la inteligencia natural se genera una diferencia de gradiente en la tensión de cada una, una burbuja, de cada vez más frecuente aparición en el flujo informativo del ciberespacio. Merece la pena dedicarle un poco de atención.

\subsection{Diálogos y consensos en la época de las burbujas informativas}

Eli Pariser en su obra titulada The Filter Bubble: What the Internet Is Hiding from You (traducida como El filtro burbuja: Cómo la web decide lo que leemos y lo que pensamos, Ed.Taurus 2017) parte de mostrar la diferencia de resultados entre dos búsquedas similares realizadas por dos personas diferentes, analizando el fenómeno de la selección mediante algoritmos de empresas como Google, Facebook o cualquier portal de noticias, y plantea las consecuencias que tiene esto sobre nuestra recepción de información y, en consecuencia, sobre nuestra forma de pensar.

Efectivamente, en diciembre de 2009, Google comenzó a personalizar los resultados de las búsquedas de todos sus usuarios, y arrancó así una nueva era en la que las webs que visitamos se van adaptando a nosotros como por arte de magia. El filtro burbuja, un libro fascinante y visionario, revela lo que hay detrás de esa ubicua personalización, desde Facebook hasta Google pasando por cualquier portal de noticias, y cuestiona sus consecuencias sobre nosotros, sobre la información que nos llega y, en última instancia, sobre el funcionamiento de la democracia. Cada uno de nosotros vive en un universo de información personalizada, una burbuja a la que solo acceden las noticias que se ajustan a nuestros intereses y preferencias, limitando la exposición a ideas, opiniones y realidades ajenas.

Internet, que dio nacimiento al ciberespacio para facilitar el flujo de ideas e información —-de discursos—, se está cerrando sobre sí mismo bajo la presión 
del mercado y la monetización. Con el uso de algoritmos personalizados el sistema de la AI presupone lo que es más relevante para ti, sobre la base de tu conducta en la web, por lo que muestra solo lo que quieres ver y filtra otras perspectivas. Este hecho se conoce como filtros de información, burbujas de información o burbujas de filtro. Esta situación no solo se da cuando se hacen búsquedas en Google, sino también con otros buscadores y servicios en la web, como Facebook, Amazon, LinkedIn. Los algoritmos que hay debajo de estas plataformas, en busca de una personalización óptima de los contenidos - y el marketing lo más directo posible-, determinan por sí solos qué estas interesado en ver y qué no, aunque tú pudieras hacerte otra idea. Los diálogos, debates, acuerdos y desacuerdos en la época de las burbujas informativas nos aíslan dentro del mismo glóbulo, o burbuja socio comunicativa.

\section{El periodismo y la posverdad}

El periodismo es hoy una profesión cuyo cometido consiste en el trabajo de recopilación, selección, tratamiento, puesta a punto y presentación de la información de actualidad a ser comunicada con una periodicidad regular, ya sea directamente a través de los Medios de Comunicación de Masas (MCM) como profesional contratado por éstos, ya sea al servicio de empresas, instituciones, organizaciones, etc., para ponerlas en contacto con sus públicos interlocutores sociales sirviéndose de la prensa, pues suelen ser periodistas también quienes trabajan en los llamados gabinetes de prensa de instituciones y empresas (Cfr. Piñuel et al., 2013).

La periodicidad regular de la información publicada, o dada a conocer a sus públicos, relatando acontecimientos y sucesos de la actualidad en uno o varios campos, es el rasgo que distingue al periodista de cualquier otro redactor profesional encargado de elaborar y distribuir informaciones puntuales, generales o especializadas (escritores, editores, guionistas, etc.); siempre y cuando aquella periodicidad (horaria, diaria, semanal, quincenal, mensual, etc.) de una publicación escrita o audiovisual, ya sea analógica o digital, venga impuesta por un compromiso: cubrir la actualidad. Siempre pueden existir publicaciones periódicas (una publicación científica, un folletín por entregas, los fascículos de una enciclopedia) a las que no se le reconocen igual función social que al periodismo, el cual disfruta en la mayoría de los países de un marco legal que regula la actividad informativa, los derechos y deberes de las personas que a ella se consagran, los derechos y deberes comprometidos como efecto de los mensajes difundidos por los medios de comunicación, así como también los derechos y deberes en los ámbitos e instituciones en que se ejerce la actividad informativa. 
Ahora bien, un panorama como el descrito en apartados anteriores, enmarca la práctica social del Periodismo de una manera que se torna asfixiante y que se asemeja a un entorno contaminado y tóxico, desde el momento en que los medios compiten entre sí en el ciberespacio, y muy especialmente a través de las redes sociales, para servir a sus audiencias. Y esa competencia entre ellos no se libra por acercarse a la verdad del acontecer, sino por adecuarse a los perfiles de cada burbuja socio digital. Se plantea entonces cómo servirse de nuevos modelos digitales de periodismo, pero defendiendo el patrimonio de sus contenidos ante el desafío que les supone enfrentarse en un espacio donde han desaparecido en gran manera los límites de propiedad. Así pues, al interior de este nuevo entorno tecnológico del ciberespacio, la tentación es buscar antes nuevas estéticas, narrativas y sensibilidades, y competir exhibiendo una mayor versatilidad frente a lo multi y transmedial de las innovaciones tecnológicas, que fortalecer la confianza en el periodismo por la búsqueda de la objetividad, sin caer en el abuso de la retórica y la manipulación lingüística de la verdad.

\subsection{Prácticas periodísticas para acercarse a la verdad}

Confiar en la prensa es una actitud que los lectores mantienen esperando estar informados de lo que ocurre en el curso del acontecer socialmente relevante. Desconfiar de la prensa, por el contrario, no provoca rechazar la información mediática, sino cuestionarla, lo cual, a veces, obliga a quien desconfía a leer más periódicos, a comparar sus discursos o buscar otras fuentes de información (Piñuel et al., 2013). En cualquier caso, desconfiar puede ser una actitud crítica y activa, pero también puede ser debida a un desinterés tanto por el curso del acontecer socialmente relevante, como a un menosprecio por los géneros mediáticos que lo narran y lo interpretan. Pero no siempre la confianza en los discursos mediáticos centrados en el acontecer socialmente relevante se sostiene por el interés que suscita la actualidad; también se afianza como consecuencia de la credibilidad que se atribuye a los medios. Y la credibilidad puede llegar a ser tan decisiva que se convierte en acontecer socialmente relevante aquello de lo que se habla en la prensa y no aquello que ocurre. Hasta tal punto, que, si algo ocurre, pero no es contado por los medios, desaparece de la percepción colectiva y llega a carecer de existencia social.

Ahora bien, ¿el acontecer de actualidad del que hablan los medios es el socialmente relevante o se está produciendo una construcción mediática de la realidad porque los medios convierten en acontecer aquello de lo que hablan? En consecuencia ¿se puede plantear la verdad de los discursos mediáticos siguiendo el criterio aristotélico de la adecuación entre discurso y acontecer? Si la vigencia del acontecer depende de la existencia del discurso que lo construye, entonces las auto-referencias en el discurso se convierten en criterio de verdad, 
hasta llegar a hacer socialmente consistentes las fake news, una expresión casi indisolublemente ligada a la de posverdad, elegida como palabra del año en 2017 por el Collins Dictionary, que la define como información falsa, a menudo sensacional, difundida bajo el disfraz de noticia. Por lo tanto, si el acontecer solo puede ser mediático, el discurso del acontecer que difunden los medios solo puede ser autorreferente. Esto es lo que puede llevar a hacer vigentes las burbujas informativas anteriormente citadas, de cuyo devenir histórico es responsable el servicio de la práctica social del periodismo.

\section{2. Ética periodística en un mundo de redes sociodigitales}

En un mundo de redes digitales conformando persistentes burbujas cada vez más aisladas unas de otras, el análisis de la responsabilidad social y la epistemología de la virtud en la práctica del periodismo (Piñuel et al., 2013), permite descubrir unas reglas de juego que embridan el sentido de nuestra existencia: reglas de juego para la acción y el discurso que marcan una estructura al acontecer posible de ser percibido, representado y pautado conforme al dominio social, en curso, de nuestra existencia histórica. De aquí la importancia de analizar cómo es la estructura del acontecer posible de ser percibido, representado y pautado conforme a ese dominio social de existencia histórica que día a día va construyendo el relato de la actualidad en los medios de comunicación, cuyo producto social es el servicio que brinda el Periodismo, pero que construye históricamente la verdad posible.

Blanco-Herrero y Arcila-Calderón (2019) abordaron una investigación para conocer si la deontología periodística ofrece una herramienta útil para luchar contra las noticias falsas. Realizaron una encuesta a 383 periodistas españoles, así como cuatro entrevistas en profundidad a expertos del área, y pudieron comprobar la percepción de la gravedad y el corte deontológico del problema de las noticias falsas, pero que la ética periodística no fue considerada la medida más efectiva para luchar contra las fake news. También se plantearon si había posibles diferencias entre las opiniones de periodistas digitales y tradicionales en su aproximación a las noticias falsas y la deontología. Ambos grupos coincidieron, no obstante, en responsabilizar del fenómeno de las fake news a la situación deprimida del sector y a las nuevas formas de comunicación (no necesariamente periodísticas) en la Red, a lo que añadieron que la formación de los consumidores podría ser una medida eficaz contra las noticias falsas.

\subsection{Nuevos modelos digitales de periodismo}

No obstante, frente a las fake news se han alzado los llamados fact checking sites - sitios para el chequeo de hechos-, dedicados a contrastar la información y comprobar falsedades: v.g. Maldito Bulo (España), Full Fact (GB) o Snopes, 
PolitiFact (USA), son sitios web que han sido promovidos fuera de los medios convencionales, pero dedicados al denominado periodismo de datos con el objeto de identificar rumores malintencionados que circulan por el ciberespacio. Pero también entre los medios convencionales hay periódicos que han instalado sus propios dispositivos de comprobación, con gran éxito algunos, como el FactChecker de The Washington Post, al que se debe haber destapado un numero detallado de falsedades localizadas en los discursos e intervenciones del presidente Trump (Fact Checker, 2017; 2019); pero también en España La chistera (El Confidencial), El cazabulos (El diario.es) o Hechos (El País); o en Francia Désintox (Libération), Décodeurs (Le Monde). Incluso cadenas de televisión, como Channel 4 (Fact check) o la BBC (Reality check) en GB; la ARD en Alemania (Faktenfinder) o La Sexta en España (El objetivo) (cfr. UfarteRuiz, Peralta-García y Murcia-Verdú, 2018).

De todos modos, en palabras de Rodríguez-Ferrándiz:

La eficacia de los comprobadores de hechos en la corrección de las misperceptions ("percepciones erróneas") está en discusión: mientras algunos sostienen que en ciertos casos refuerzan más que corrigen aquello cuya veracidad discuten, es decir, exacerban el sesgo de confirmación de quien había asumido el fake (el backfire effect, Nyhan; Reifler, 2010); otros destacan su capacidad para revertir la situación y servir a los fines de una pedagogía informativa (Porter, 2017) (Rodríguez-Ferrándiz, 2019).

Modelo digital contrario, surgido para el aprovechamiento de fake news es el del falso periodismo, el debido a los bots o difusión masiva de noticias que se asemejan en su formato a piezas periodísticas, y que son redactadas de manera robotizada conforme a algoritmos de AI (Inteligencia Artificial). El bot es un término aféresis de robot y remite a programas informáticos que efectúan automáticamente tediosas tareas de repetir noticias variando solamente aquellos segmentos textuales seleccionados conforme al perfil estándar del usuario a quien se destinan.

En esta misma línea, fue célebre la irrupción de las fake news así difundidas según las sospechas fundadas de graves injerencias de una fábrica de estos productos tóxicos radicada en San Petersburgo, la Agencia Rusa de Investigación de Internet, en la campaña presidencial norteamericana de 2016. Dichas piezas desinformativas habrían influido en amplias franjas del electorado estadounidense a través de Facebook principalmente, y habrían distorsionado el debate público a favor de Donald Trump, denigrando a Hillary Clinton y propagando la discordia general, aspectos que recogió ya el 6 de enero de 2017 la US Intelligence Community, una federación de dieciséis agencias gubernamentales de inteligencia en relaciones internacionales y en seguridad nacional, y que en 
mayo de 2018 el Senado norteamericano validó (Demirjian, 2018; Petit, 2018; citados por Rodríguez-Ferrándiz, 2019).

Este inestable territorio de los discursos periodísticos en el ciberespacio recrudece el debate de los derechos de propiedad de contenidos y de soportes, pues el clipping (el originalmente conocido como el quehacer de recopilar y publicar recortes de prensa), ya automatizado por los buscadores en Internet, le facilita la tarea a los bots.

\subsection{Derechos de propiedad de contenidos y de soportes}

La tecnología digital del ciberespacio pone en cuestión muchos aspectos de las Leyes de Propiedad Intelectual, especialmente después de los nuevos tratados mundiales, lo que conduce a reflexionar sobre la vigencia del sistema tradicional de derechos de autor. Aunque según la Ley de Propiedad Intelectual en muchos países y tratados internacionales, el soporte de una obra no debería afectar a su protección, es evidente que los nuevos soportes generan nuevas modalidades de explotación, llegando a modificar casi todos los conceptos legales: por ejemplo, el concepto de obra, de autor, de atribución de autorías y derechos morales, económicos, así como a la transmisión de derechos, a los sistemas de protección y a los sistemas de gestión.

A pesar de que, en los inicios de Internet, hubo quienes pronosticaban el fin del derecho de autor, el sistema ha probado su capacidad de resistencia, y muchos intereses económicos de por medio hacen, a pesar de todo, muy difícil su desaparición. Se tendrá que crear, pues, un nuevo marco normativo que, aceptando el cambio, regule la compleja relación entre los titulares de los derechos y los usuarios, que es donde realmente radica hoy el problema de los derechos de autor. Pero las nuevas tecnologías son fundamentalmente nuevos medios y/o soportes y, por lo tanto, atañen a la posibilidad de nuevas modalidades de explotación de las obras.

\subsection{Estéticas, narrativas y sensibilidades en el nuevo entorno tecnológico}

La aparición y el cambio de nuevas modalidades de explotación de las obras en el ciberespacio conducen a explorar estéticas, narrativas y sensibilidades adaptadas a los perfiles de los usuarios a quienes se destinan. En psicología, se conocen como rasgos de personalidad, los llamados cinco grandes (Big five). Estos factores constitutivos fueron reportados durante un estudio sobre las descripciones que hacían unos individuos sobre la personalidad de otros (Goldberg, 1993), y es uno de los modelos sobre los rasgos de personalidad humanos más reconocidos. 
Los cinco grandes rasgos de personalidad, también llamados factores principales, suelen recibir los siguientes nombres: factor 0 (apertura-openness - a las nuevas experiencias), factor C (responsabilidad - o charge-), factor $\mathrm{E}$ (extroversión), factor A (amabilidad) y factor $\mathrm{N}$ (neuroticismo o inestabilidad emocional), formando así el acrónimo OCEAN ${ }^{3}$. La historia de la Teoría de la personalidad de los cinco grandes se inició cuando varios grupos de investigadores independientes descubrieron y definieron los factores mediante investigación empírica basada en datos. Ernest Tupes y Raymond Christal (1950) aportaron el modelo inicial, basado en el trabajo realizado en el Laboratorio de Personal de las Fuerzas Aéreas de los EE. UU. en la década de 1950. Digman (1990) propuso su modelo de los cinco factores de personalidad en 1902, y Goldberg lo llevó a los niveles más altos de las organizaciones en 19934.

Según cuenta Rodríguez-Ferrándiz (2019), Michal Kosiński, experto en psicometría de la Stanford University, elaboró en 2008 un protocolo para analizar a los usuarios de la Red a partir de su actividad en Facebook. Solo tenía la intención de enviar su protocolo a unas pocas decenas de sujetos para obtener resultados de investigación, pero luego se vio abrumado por el índice de respuestas de su encuesta, que se viralizó y fue respondida por 58.000 informantes. En 2013 logró demostrar que, sobre la base de un promedio de 68 likes otorgados en Facebook por un usuario, era posible predecir su color de piel (95\% de precisión), su orientación sexual (88\%) y su tendencia política (demócrata o republicano, con un 85\%). Añade Rodriguez-Ferrandiz (2019) que Kosiński rechazó la oferta de integrarse en una empresa, Strategic Communication Laboratories Group (SCL Group), radicada en Londres, dedicada a estrategias de difusión de información política, campañas sociales, así como puramente comerciales. Cambridge Analytica fue precisamente una spin-off de SCL Group.

Rodriguez-Ferrandiz (2019) sigue proporcionando otros datos: entre los directivos de Cambridge Analytica, estaba Robert Mercer, multimillonario y donante generoso en las campañas republicanas, que fue el fundador de la empresa, y Steve Bannon, que fue su vicepresidente. En 2016, la empresa pudo haberse hecho con hasta 220 millones de perfiles de personalidad basados en pruebas OCEAN, así como paquetes brutos de datos personales comprados a terceros, como Acxiom y Experian. Pero además estas maniobras no se limitan

\footnotetext{
${ }^{3}$ Según puede consultarse en https://www.123test.com/es/teoria-de-la-personalidad-de-loscinco-grandes, donde se ponen a disposición formularios para los test.

4 En una prueba de personalidad, para hacer referencia a los rasgos de los Cinco Grandes, también se puede utilizar el Modelo de los Cinco Grandes, conocido como FFM por sus siglas en inglés Five Factor Model (cfr. Costa y McCrae, 1994; Russell y Karol, 1994).
} 
a los contenidos e informaciones en el ciberespacio, se extienden al diseño y planificación de los soportes y en estas estratagemas compiten los medios tradicionales haciéndose presentes en Internet a través de las redes sociales, de los blogs, del uso de pantallas multi y transmediales, etc.

\subsection{Los medios masivos frente a lo multi y transmedial}

En los últimos años, gracias a las innovaciones tecnológicas, y como ya lo hemos expuesto en otro lugar (Piñuel y Arrojo, 2014), la creatividad desarrollada en el ámbito de los soportes digitales de los medios de comunicación de masas ha provocado impresionantes cambios comunicativos, que no tienen precedentes en las sociedades occidentales. Estos cambios comunicativos se pueden apreciar en seis aspectos principales: (i) los contenidos comunicativos en formato digital combinando texto y vídeo; (ii) las estrategias de programación (en redes sociales y plataformas web); (iii) los procesos de producción, combinando realización y agitación (influencers con millones de seguidores); (iv) los mecanismos de distribución (combinando plataformas propias y redes sociales, como Facebook, Instagram, YouTube, etc.); (v) las vías de financiación (publicidad y mercado online); y (vi) los usos que las audiencias hacen de esos contenidos (likes y comentarios en multitarea y multipantalla). La tendencia es a la producción y circulación audiovisual adaptada a la versatilidad multipantalla transmedial e interactiva.

Según Sara Ortells-Badenes (citada en Piñuel y Arrojo, 2014) esta tendencia favorece la proliferación del uso de vídeos por parte de los cibermedios. Si bien es cierto que su presencia se incrementa notablemente en los últimos años, no todos los medios de comunicación lo integran del mismo modo. Micó-Sanz y Masip (2008), citados por Sara Ortells-Badenes (en Piñuel y Arrojo, 2014), distinguen cuatro grandes tendencias en el panorama español, pero que actualmente se están generalizando cada vez más: 1) Portales informativos de medios audiovisuales que aparte de ofrecer contenidos en formato vídeo también apuestan por la integración de otros recursos multimedia. 2) Periódicos que van integrando vídeos en sus contenidos, reduciendo progresivamente los contenidos en formato texto, que se comercializan para suscriptores. 3) Cibermedios que habilitan canales televisivos online asociados a su publicación. 4) Periódicos que dan un giro y abandonan las noticias en formato texto para convertirse en contenedores de vídeos.

En lo que respecta al tipo de vídeo-noticias, las posibilidades son ilimitadas, siguiendo la propuesta de López (2008) y Bradshaw y Rohumaa (2011) estos son los formatos más comunes, según Sara Ortells-Badenes (en Piñuel y Arrojo, 2014): 
1. Noticias en formato vídeo: se trata de piezas informativas que normalmente proceden de agencias periodísticas, de medios tradicionales o de YouTube. Suelen presentarse embebidos en noticias que combinan texto y vídeo.

2. Vídeo-noticia de producción propia: se trata de vídeos (VTR) completos que, además de imagen, pueden contener voz en off, entrevistas y gráficos que ayuden a ilustrar la noticia. Realizados por el propio medio.

3. Vídeo guías: se trata de vídeos que enseñan a los usuarios a hacer diferentes cosas, ya sean manualidades, recetas o a utilizar aparatos electrónicos.

4. Vblogs: diseño de blog dentro del cibermedio que solo incluye vídeos.

5. Streaming: retransmisiones en directo que pueden seguirse a través de la red.

6. Programas realizados exclusivamente para ser difundidos a través de la red.

A pesar de que el peso del vídeo en las publicaciones online sigue creciendo, demostrando una sensibilidad notable por el uso de este tipo de contenidos, resulta curioso destacar que recientes investigaciones demuestran que la utilización de vídeos de producción propia continúa teniendo una presencia todavía residual — de uno de cada tres vídeos - siendo aquellas informaciones procedentes de fuentes ajenas las que siguen manteniendo una presencia mayor (Mayoral y Edo, 2014). La cuestión es si crece o disminuye la confianza en el periodismo.

\subsection{Cómo fortalecer la confianza en el periodismo}

Cabe considerar el servicio público de la producción, distribución y consumo de información sobre la actualidad, como una manifestación de la autopoiesis que se lleva a cabo en el marco de un dominio de existencia que corresponde a nuestro momento histórico. ¿Qué quiero decir? Siguiendo a Maturana, H. y Varela, F. (1973 y 1996) se puede plantear cómo es posible reconocer nuestra permanencia (nuestra propia existencia) mientras nuestro entorno va cambiando; y a la inversa, cómo es posible reconocer la permanencia del entorno, mientras somos nosotros los que vamos cambiando. Y, más aún, cómo recíprocamente vamos cambiando sujetos y entornos en la medida en que desarrollamos actuaciones respondiendo a los cambios del entorno, y también en la medida en que nuestros entornos se modifican como consecuencia de nuestras actuaciones.

Lógicamente, estos procesos recíprocos van construyendo un dominio (biológico y social) de existencia que en la ciencia actual se denomina autopoiesis; este término procede de las palabras griegas auto ( $\alpha v \tau o$ que significa propio

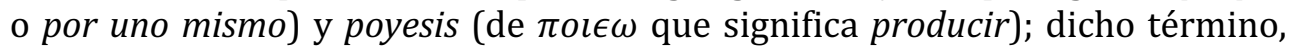
autopoiesis, sirve para referirse precisamente a ese proceso recíproco por el cual las actuaciones de los sujetos sobre los entornos, y los cambios de los 
entornos sobre los sujetos, producen aquellos dominios de existencia que evolucionan recíprocamente. Pues bien, cuando los cambios en la autopoiesis resultan socialmente relevantes, lo podemos entender como dominio del acontecer y en sus condiciones psico-biológicas, se implican procesos de memoria y anticipación de datos; y en este sentido, las condiciones cognitivas del acontecer tienen que ver con el recuerdo, la evocación de experiencias y los proyectos de actividad; las condiciones sociales del acontecer, entonces, atañen a los procesos reproductivos de apropiación del entorno de la denominada autopoiesis de los dominios sociales de existencia. La responsabilidad del periodismo, pues, tiene así que ver con la estructura del acontecer posible de ser percibido, representado y pautado conforme a ese dominio social de existencia histórica que día a día va construyendo el relato de la actualidad en los medios de comunicación de masas. Y en el caso que nos ocupa en el ciberespacio.

Para plantear cómo fortalecer la confianza en el periodismo, se debe:

- Poner en relación la comunicación con la interacción social y colocar la interacción social en el universo de posibilidades y previsiones extraídas de las condiciones que nos conciernen como individuos y ciudadanos y que tienen su existencia en las condiciones históricas de los cambios sociales, es decir, de autopoiesis de nuestro dominio social de existencia.

- Vincular la evolución de la vida y la sociedad con el acontecer histórico de la comunicación y las virtualidades que la comunicación ofrece en la construcción de las representaciones sociales que son construidas por el juego de la reflexividad entre discurso y acción.

- Hacer uso de este planteamiento para actuar sobre el Periodismo, dotando entonces a esta práctica social de dimensiones desconocidas que lo colocan frente a su más grave responsabilidad histórica: su cooperación a la construcción y la reproducción de nuestro dominio social de existencia.

Por consiguiente, la idea de que los valores atribuidos a la información (v.g. la verdad, el conocimiento) se transforman en valores sociales relevantes remite a poner de manifiesto la responsabilidad de los medios de comunicación en la tarea de la construcción social de la realidad.

Esta reflexión sobre los nuevos retos de la comunicación al estudiar la hegemonía pública de los discursos sociales que circulan en las redes emergentes de Internet, donde los medios de comunicación tradicionales pueden dejar de ser los principales agentes proveedores de información, garantes del control institucional y responsables de la reproducción social a la que contribuyen, se torna de vital importancia, ya que comunicar diciendo la verdad siempre ha sido una de las grandes aspiraciones de la honradez y la integridad humanas. 
La verdad, en principio, permite establecer la conformidad entre los que se comunican, en torno a lo que dicen, lo que sienten o lo que piensan a propósito de lo que ocurre o existe. Ahora bien, cuando se cuestiona decir la verdad no solo se requiere apelar a la ética, sino también a tener en cuenta las necesidades biológicas y culturales de la comunicación (Cfr. Piñuel et al., 2013).

Solo nuestra especie es capaz de engañar, atribuirse errores en los procedimientos cognitivos y comunicativos, y desechar como falsedades construcciones de su pensamiento. Ninguna otra especie animal con la capacidad de comunicarse puede plantearse si la comunicación es verdadera. Por lo tanto, la distinción del valor de verdad al comunicar es connatural a la especie humana cuya evolución se encuentra muy ligada a las virtualidades de la comunicación, ya que de ella depende directamente la construcción del capital cognitivo por el que sobrevivimos como especie social, y es este capital cognitivo el que constituye nuestro dominio de existencia. La comunicación, desde un punto de vista biológico, permitió a algunos seres vivos construir un dominio de existencia propio de la especie, al que se incorporaron determinadas habilidades congénitas para explotar las oportunidades que les brindaba el entorno recurriendo a la tele-interacción por señales. En la conducta humana, en cambio, la comunicación no es una habilidad heredada genéticamente, sino aprendida individualmente como un comportamiento específico determinante en la evolución del individuo (en su maduración personal y social), pero también en la construcción de identidades, hábitos, escenarios e imaginarios sociales, sin los cuales ni el conocimiento compartido, ni las relaciones humanas en sociedad se pueden reproducir, lo cual constituye ya un dominio social de existencia.

Resulta hoy día comúnmente aceptado que aquello que publican los medios de comunicación de masas sobre los aconteceres de actualidad se torna en una realidad que los ciudadanos acaban percibiendo como la más relevante socialmente, y que lo no referido por los MCM carece de percepción colectiva. Por ello, el discurso de los MCM constituye el objeto de análisis al que habitualmente se recurre para conocer la imagen colectiva que las audiencias pueden compartir cuando cualquier actor social se hace presente en los aconteceres de actualidad. Enfrentarse a la cuestión de la Retórica y de la manipulación lingüística de la verdad adquiere entonces una dimensión biológica y ecológica.

\subsection{Retórica y manipulación lingüística de la verdad}

Permítaseme seguir glosando reflexiones ya iniciadas en mi obra Confiar en la prensa o no (Cfr. Piñuel et al., 2013). La vigencia o caducidad de la información que refiere o cuestiona la verdad de las cosas depende de los hábitos mentales que realizan los sujetos para diferenciar las certezas o las incertidumbres de lo 
que saben: la dicotomía certidumbre / incertidumbre es en realidad una doble representación sobre los conocimientos disponibles por los sujetos; es decir, es una imagen que establece la confianza sobre representaciones de objetos, situaciones, acciones... Si se confía en estas imágenes, jhay certidumbre! si se desconfía, ¡hay incertidumbre!

El procedimiento mental más habitual que utilizan los sujetos para diferenciar la seguridad, de la inseguridad, son las creencias o ideas compartidas que pueden estar fundamentadas en actitudes solo generadoras de confianza ingenua en una verdad o falsedad aceptadas colectivamente, o bien en la confianza socialmente atribuida a una forma de expresarla: ya sean relatos que $e x$ plican el curso del acontecer compartidos por iguales dentro de la burbuja informativa, ya sea el discurso científico cuyas leyes formales se exige sean sometidas empíricamente a examen de validez.

Si pretendemos imaginar el origen del lenguaje, los primeros ejercicios de pensamiento que llevó a cabo el sujeto genérico (o colectivo) serían aquellos vinculados a un discurso corporal y sonoro que promoviese confianza en el manejo de aquellos objetos más familiares, más recurrentes en su interés, o que más le merecían la pena convertir en los primeros objetos de conocimiento seguro. La representación establecida en aquellos incipientes procesos discursivos dio origen tanto a los mitos como a las ciencias, aunque éstas surgieron muy posteriormente. En un principio no había diferencias entre ambas dinámicas del saber seguro. Hoy en día podemos afirmar que la ciencia y el mito no sólo son procedimientos totalmente distintos para establecer conocimientos seguros sobre los temas de los que se ocupan, sino que además siguen coexistiendo.

Cuando se cuestionan las condiciones de la comunicación verdadera es necesario saber si la información utilizada es vigente u objetiva, pertinente o significativa, fiable o válida. No hay que perder de vista que estamos hablando de la comunicación, o sea, de una interacción humana que se hace posible por la circulación de expresiones (discursos); ahora bien, ¿siempre que hay circulación de expresiones hay comunicación? Es obvio que no, puesto que solo la puesta en circulación acústica de expresiones sonoras que realiza el lorito no es comunicación; para que haya comunicación, es necesario que haya discursos, es decir, que la circulación de expresiones suponga una alternativa particular de interacción, entre las alternativas de interacción previamente posibles en un dominio de existencia. Los sujetos de una interacción comunicativa nunca la emprenden por tanto a partir de cero.

El saber hacer acerca de la comunicación es un patrimonio cognitivo del sujeto genérico, es decir, es un producto de la práctica comunicativa, que se almacena en la memoria de los sujetos individuales en función de su aprendizaje 
particular y contingente, y que, cuando éstos entran a tomar parte de una interacción comunicativa, se activa en forma de esquemas previos, que guían la construcción recursiva de sus representaciones de segundo orden (podríamos denominarlo capital comunicativo disponible). Los esquemas que poseemos acerca de los demás (esquemas sociales), contienen datos que no sólo se refieren a las propiedades de identidad del sujeto, sino también a la posición que ocupan (estatus) y a la función que desempeñan (rol) dentro de los grupos y organizaciones sociales, es decir, en su calidad de agentes de un sistema social. Esos datos pueden hacer que nos comportemos de una u otra manera.

Cualquier discurso comunicativo (conversación interpersonal, libro de texto, conferencia académica, correo electrónico, carta postal, chat informático, debate televisivo, etc.) se construye mediante la circulación de expresiones; la fiabilidad, pertinencia y objetividad de dichas expresiones no se ponen en duda, pues de lo contrario sería imposible que los interlocutores pudiesen meta-comunicarse, es decir, alcanzasen acuerdos sobre la comunicación más allá de lo que se expresa. Para evitar el continuo cuestionamiento de las expresiones, y tener que hacer continuamente acuerdos sobre la comunicación, el saber hacer acerca de la comunicación (patrimonio cognitivo de la sociedad) cuenta con recursos para reforzar la confianza en los discursos, superando las estrictas condiciones de verdad formal y verdad material que tanto han preocupado a los teóricos del conocimiento. La cuestión que entonces conviene plantearse es si más allá de la Epistemología o Teoría del conocimiento seguro, debe ocuparse del problema el Estado de Derecho.

\section{Nuevos sistemas de Comunicación en el Estado de Derecho}

Contemplando el panorama del ciberespacio anteriormente descrito, las nociones de verdad que de forma tan importante se encuentran vinculadas a la reproducción de nuestro dominio social de existencia, deben ser objeto de examen desde un Estado social de Derecho a defender y mejorar. Y será ineludible explorar y acechar por dónde se acercan sus amenazas entre las cuales están las nuevas formas de comunicación surgidas de las nuevas economías por medio de las cuales se crean los productos y mercados en el ciberespacio: examinar entonces los vicios y virtudes de la cibereconomía. Respecto a este término es legítimo proponer una revisión sustituyéndolo por el de economía del ciberespacio, pues la comunicación y el control propio de la reproducción de sistemas vivos y de máquinas al que remite el término de cibernética, propuesto por Norbert Wiener, como se ha comentado al principio de esta exposición, puede ser referido al espacio virtual de las transmisiones digitales de datos, pero la 
economía no es un espacio sino un saber hacer saber para la producción, reproducción y trasmisión comercial y mercantil de bienes y servicios, que es considerada generalmente una ciencia. De todos modos, al abordar el examen de la economía del ciberespacio, uno de los hechos más reveladores de ese saber hacer saber que se conoce como economía respecto a la circulación de bienes y servicios propios del ciberespacio, es la vulnerabilidad de la verdad y la manipulación, de las cuales ha habido una triste experiencia ante la emergencia del cambio climático. Aconteceres como el hacer de un riesgo planetario cuestión de debate ideológico y de diatriba política, amenaza la condición de ciudadanía en función de la cual se reconoce a cada usuario de la circulación de discursos en el ciberespacio sus derechos de inclusión y participación democráticas. Y una vulnerabilidad como ésta, reclama de los poderes públicos una especial atención sobre las garantías a respetar y defender en la comunicación política, gubernamental y en definitiva ante la circulación de discursos en el ciberespacio, lo que a veces se permite llamar ciberpolítica.

Cuestiones como el derecho al acceso de la información, los modos de exigir la transparencia en la información gubernamental, o las perturbaciones que genera la ciberpolítica al examinar los efectos que sobre ella producen las redes sociales y sus burbujas de filtro informativo, especialmente en los procesos electorales, se tornan cuestiones de gran transcendencia para las democracias. Quizás convenga volver la mirada finalmente hacia las utopías imaginadas en los años setenta en torno a la comunicación comunitaria, alternativa y popular, pero esta vez tras haberse enfrentado a los escenarios de posverdad. Vayamos por pasos

\subsection{Nociones de la verdad en la era digital}

Mediante la construcción y renovación permanente de la confianza que garantizan los discursos sociales disponibles, la comunicación - como hemos expuesto Piñuel et al. (2013) — hace posible la autopoiesis o reproducción dialéctica de los objetos de conocimiento (objetos vigentes, significativos y válidos en un dominio de existencia histórico) y del sujeto genérico (el sujeto epistémico que sustenta el pensamiento seguro sobre los objetos). Ninguna verdad se encuentra absolutamente construida y definitivamente acabada. La confianza así sostenida por los discursos sociales, por las prácticas relevantes que llevan a cabo los sujetos debido a esta confianza, y por la vigencia otorgada a los objetos de conocimiento que se van renovando como consecuencia de estas prácticas y de aquella garantía de los discursos sociales, hace que cualquier verdad sea históricamente provisional, se vaya retocando, creciendo, y también limpiándose, perdiendo adherencias. 
El sistema actual de comunicación social transforma y devalúa la verdad, porque cada vez es más débil la exigencia de contrastar la información. ¿Qué es verdadero y qué es falso? Si todos los medios de comunicación afirman que algo es verdadero, entonces, por mayoría, ¡será cierto!, aunque sea falso. Es decir, si la información no contrastada se toma por objetiva, y si además periodísticamente aparece como significativa porque se la supone de interés general para las audiencias, entonces será válida a todos los efectos. En este sentido Ignacio Ramonet comenta que:

[...] la verdad, aunque no siempre sea fácil determinarla, es un criterio que debería tener una cierta pertinencia en lo referente a la información. Se debería considerar que tiene algo que ver con la información. Ahora bien, hoy en día al sistema no le sirve de nada la verdad. Considera que la verdad y la mentira no son criterios pertinentes en temas de información. Actúa de forma totalmente indiferente ante la verdad o la mentira (Ramonet, 2002: 5).

La verdad y la mentira han variado, se entienden de otra forma o aún no hemos abandonado la época en la que las creencias más arraigadas son más influyentes que las demostraciones científicas. Las creencias dentro de la propia burbuja informativa pueden ser más poderosas que la verdad formal o material de la expresión comunicativa, y por lo mismo pueden llegar a ser inamovibles y sordas ante su consistencia formal o su certeza empírica. Podemos preguntarnos entonces: ¿Una buena demostración es suficiente para que una persona, una comunidad, un grupo cambie de opinión? El criterio del cambio de opinión no es un problema filosófico, sino comunicativo. Si una demostración es consistente (formal o empíricamente) ¿puede ser rechazada? Sí. En la comunicación, los interlocutores pueden aplicar criterios por los cuales aceptan o rechazan una expresión verdadera (una demostración filosóficamente correcta) que se derivan del miedo, la vergüenza, la soberbia, etc. Inversamente un cambio de opinión, activado por estos resortes irracionales, no podría ser denunciado si no fuese demostrando qué hay de racionalidad en la expresión. Las audiencias (receptoras de incertidumbres recurrentes) no tienen más criterios de apreciación, orientación y comparación que las informaciones de los diferentes medios de comunicación, y si todos dicen lo mismo, las audiencias están destinadas a admitir esa verdad.

Muchas organizaciones (instituciones y empresas) invierten grandes sumas de dinero contratando investigaciones que les permitan conocer cuál es el discurso que los medios de comunicación de masas convierten en hegemónico a la hora de describir sus imágenes identitarias y las actividades (económica, política, cultural, sanitaria, etc.) a las que se dedican. Esta práctica social de los media no sólo supone la creación de un discurso que se torna hegemónico (con 
agendas temáticas prediseñadas) sino, sobre todo, que es responsable de generar un acontecer mediático que adquiere una existencia autónoma (independiente de la naturaleza de los hechos de los que se habla) y frente al cual los actores sociales terminan viéndose comprometidos.

Si la producción de comunicación de la industria mediática desempeña sus funciones de interés público a la hora de seleccionar temas de actualidad, sometidos a previsiones de agenda (Agenda Setting), y los presenta conforme a enfoques o perspectivas de interés estratégico para incrementar la credibilidad del discurso y de sus actores (Agenda Framing), se puede estar generando una segunda realidad superpuesta al acontecer. En este sentido, los media relatan (legitiman con su discurso) y suplantan el universo originario de los hechos relatados: es la comunicación la que se torna en acontecimiento, es el discurso hegemónico el que se convierte en realidad social. Este planteamiento sirve para ir más allá del estudio de los referentes mediáticos (tematización, jerarquía y encuadre estratégico) como valores sociales, y para examinar los objetos, aconteceres y valores comunicativos (discursos éticos y morales) como los principales y más interesantes referentes de los aconteceres sociales.

Si la comunicación social se torna en tema de actualidad, es porque sus actores, sus discursos, sus eventos en general (ruedas de prensa, declaraciones, filtraciones off de record, e incluso rivalidades entre grupos mediáticos) se convierten en acontecer relevante. Y un acontecer relevante termina comprometiendo tanto a los agentes sociales, que compiten entre sí por ocupar el proscenio de la actualidad mediática, como al propio repertorio temático de la agenda pública al que cada vez suben con más frecuencia los aconteceres de esta realidad superpuesta de los enfrentamientos comunicativos. Averiguar cómo se construye la agenda pública, a partir de la agenda mediática —es decir, a partir de los aconteceres de referencia que giran en torno a las rivalidades, escenarios, discursos y avatares de la propia comunicación social, sobre todo a través de las redes sociales-, adquiere ahora una especial trascendencia cuando se advierte que, cada vez con mayor frecuencia, se sustituye la primera (agenda pública) por la segunda (agenda mediática). Se trata de un proceso de mediación (Piñuel, 1989; Piñuel y Gaitán, 1995; Piñuel y Lozano, 2006) en el que se impone la llamada lógica de la simulación que

[...] no tiene ya nada que ver con la lógica de los hechos. Hay una precesión [anteposición] del modelo sobre el hecho. No se trata ya de interpretar falsamente la realidad (ideología) sino de actuar como si la realidad (real) ya no fuese necesaria (Baudrillard, 1984).

Se trata, pues, de hacer verdadero lo que se tiene por real, y de hacer real lo que se presenta como verdadero: efecto verdad versus efecto realidad. El 
efecto verdad es la verdad de la realidad mediada. El éxito de esta práctica está basado en gran medida en ofrecer veracidad y credibilidad, es decir, legitimidad. La verdad se dice o se cree, es una cuestión de lenguaje más que de ontología. El efecto realidad es la realidad de la verdad mediada. Nos encontramos ante una súper-realidad (o realidad superpuesta), la simulación que vacía al signo de valor simbólico y a la realidad la vacía de referencias reales.

Teniendo en cuenta la repercusión social de esa nueva realidad superpuesta, es decir, de las representaciones colectivas y las corrientes de opinión que pueden derivarse del discurso hegemónico que difunden los media especialmente a través de la redes sociales, la reflexión sobre las nuevas funciones sociales en torno a la producción de realidad que los medios asumen en el ciberespacio, remite a aquel universo de la referencia con el cual más se vinculan y se comprometen: el universo del discurso, el de la comunicación y el de la imposición de su verdad.

El interés del acontecer en curso que relatan los medios en el ciberespacio sobre el discurso y la comunicación se centra en la actividad que los propios medios desarrollan compitiendo entre sí por legitimarse como institución social que establece la agenda pública, es decir, que dicta aquello que constituye la verdad informativa. Y si la práctica social de los medios elabora un discurso público que se torna hegemónico, entonces los objetos, los aconteceres y los valores mediáticos - segunda realidad superpuesta al acontecer que se relata - referidos a la comunicación, se convierten en referentes sociales que adquieren una existencia autónoma -independiente de la naturaleza de los hechos de los que se hablay frente a los cuales los actores sociales terminan reconociéndose comprometidos. El discurso auto-referente que los medios convierten en hegemónico transforma así las condiciones de verdad y de realidad del acontecer frente al cual los agentes sociales se encuentran involucrados.

\subsection{Comunicación y nuevas economías: productos y mercados en la cibereconomía}

Algunos de los escenarios cotidianos más frecuentados para conectarse al mundo a través de una pantalla audiovisual van cambiando. Mientras la pantalla que ocupaba antes el escenario central del hogar, antes llamada de sobremesa, es cada vez más grande y de formato más panorámico y espectacular (hasta de 82" - pulgadas - en la actualidad), otras se van tornando cada vez más ligeras y transportables como es el caso de las pantallas del ordenador portátil, las tablets y la del teléfono móvil. Si se comparan el número de los usurarios que simultáneamente se reúnen para disfrutar de un mismo relato, encontramos que los dispositivos de mayor tamaño se destinan a convocar a grupos formados 
por un mayor número de personas, mientras que aquellos dispositivos más pequeños se acomodan a la medida de las posibilidades de cada individuo: posibilidades de manejo/operatividad, el tiempo personal de dedicación y la disponibilidad de cualquier espacio que haga posible un aislamiento mínimo, dando lugar a lo que conocemos como dispositivos en movilidad.

Pero estos escenarios (que en el Gráfico 4 se pueden ver integrando hoy en diversas proporciones el equipamiento doméstico en España), por supuesto no se ponen al alcance exclusivamente de forma simultánea, secuencial y directa conforme a parrillas de programación, sino a la carta y brindándole al usuario la posibilidad de penetrar en ellos para intervenir interactuando y contactar así con cualesquiera otros actores del relato y cualesquiera otros agentes consumidores, intercambiando opiniones y mensajes audiovisuales en una conversación de discurso poliédrico y en forma de red (red de amigos, de followers, de conversadores...).

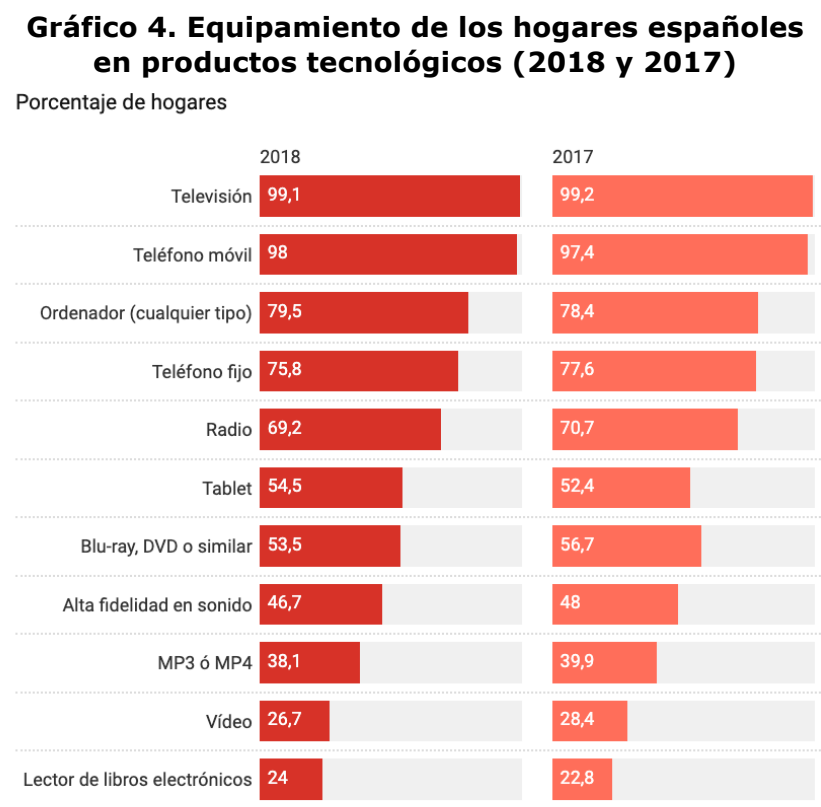

Fuente: INE, 2019.

La disponibilidad de estos discursos multi-pantallas, requiere, sin embargo, de una industria tanto más compleja en la producción de servicios (conexión, trasmisión de datos, etc.), cuanto más sencillo e individual resulte ese escenario en su accesibilidad, operatividad y familiaridad de consumo para el usuario. La industria informática, la red de Internet, la telefonía móvil, la 
capacidad de gasto en equipos y en suscripción, etc. constituyen la infraestructura imprescindible, cuyo éxito empresarial y de oportunidades de mercado se incrementa exponencialmente con el consumo del espectáculo audiovisual que brindan esos escenarios tan próximos y personales. Y podemos preguntarnos: ¿para qué se usan, y cómo, tales pantallas, tales aparatos, mientras se ve, por ejemplo, la televisión? Gracias a la convergencia de los medios de comunicación convencionales dentro de las redes sociales, asistimos a nuevas formas de consumo de los contenidos mediáticos, es decir, al denominado consumo social (Quintas-Froufe y González-Neira, 2014). Tanto el consumo de contenidos de radio y televisión a través de las redes sociales, como las posibilidades de que la audiencia pueda interactuar entre sí y con los emisores intercambiando opiniones escritas y mensajes audiovisuales en una conversación polifónica y extendida como una malla tejida de amigos, de followers, de conversadores, ha dejado obsoleto el paradigma de consumo tradicional. Hace unos años un televisor, aunque era el aparato más popular del hogar, era realmente limitado comparado con los actuales en el mercado: solo servía para ver lo que emitían las cadenas de televisión, para jugar a la consola, o para ver vídeos propios. Pero su evolución ha sido tal que ahora, lejos de ser una caja emisora de contenidos, es todo un centro multimedia con el que, además de disfrutar de canales, películas y juegos, se puede interactuar y obtener todo tipo de información en tiempo real.

Hace poco más de cinco años, los televisores con Smart TV han cambiado el juego, y, ahora, llega Android TV, la pieza que faltaba para completar definitivamente el concepto de televisor inteligente. El término de caja tonta que se ganó el televisor en décadas pasadas ya ha pasado a la historia. Ahora un televisor conectado a Internet es de todo menos tonto. Muchos usuarios de un televisor con funciones de Smart TV usan este dispositivo con otros fines realmente distintos a los que tendría un televisor convencional. Firmas como Sony o Philips se están animando a lanzar modelos de televisores con Android instalado.

Android, el mismo sistema que usan muchos smartphones y tablets, es tan versátil que puede ejercer de sistema para un televisor de última generación sin inconvenientes más, y uno de sus secretos es la potencia de Google Play, la tienda de aplicaciones que usa Android para encontrar todo tipo de aplicaciones, juegos, películas, música y libros. Con Google Play se puede encontrar aplicaciones adaptadas exclusivamente para el televisor. Se puede usar el televisor con Android TV como centro de notificaciones - para saber qué emails hemos recibido, e incluso para saber si alguien nos ha hablado por WhatsApp-, también podremos consultar noticias en tiempo real, o saber el tiempo en cualquier lugar del planeta. Pero lo más interesante es que con Android TV se contará con 
56

un centro multimedia a otro nivel gracias a estas aplicaciones. Podremos interconectar los dispositivos que tengamos conectados a una red WiFi gracias a funcionalidades como Google Cast, y compartir contenido multimedia como vídeos o fotos al instante entre ellos.

Otra manera de aprovechar Android TV es usando sus posibilidades de búsqueda por voz: podremos preguntar cuál es la cartelera de cine de nuestra zona, cómo está el tráfico en un punto concreto de la ciudad, o saber qué tiempo hará mañana y ver el resultado en la pantalla de nuestro televisor.

Según la undécima edición del Informe Anual Televidente Now, de The Cocktail Analysis (2018), los principales resultados en la evolución del consumo audiovisual son los siguientes:

- Por primera vez, el número de internautas que tienen Smart TV es superior a los que no la tienen, un $57 \%$ frente al $49 \%$ de 2017. Además, un $85 \%$ de los usuarios lo conectan a Internet, con más de la mitad de los internautas usándola durante la semana.

- Los internautas dedican más de 4 horas de media a la semana al consumo de vídeo sobre smartphone y un 37\% declara que incrementaría su uso si dispusieran de datos ilimitados.

- El $62 \%$ de internautas posee algún tipo de suscripción de pago, frente al $51 \%$ de 2017, tanto de plataformas de videostreaming (OTT) como de televisión de pago (IPTV).

- Las OTT se fortalecen y triunfa el modelo de pago compartido. El 90\% de los internautas señala que conoce la existencia de plataformas como Netflix y HBO, mientras que el $45 \%$ lo usa actualmente y un $36 \%$ paga por utilizarlo.

- El mercado de la televisión de pago por Internet (IPTV) se encuentra dominado (en España, claro) por Movistar +, que posee un 54\% del total.

- En la actualidad, el 87\% de los televidentes ven canales de TDT y las horas clave de consumo se encuentran entre las 20:00 y la 01:00 de la madrugada. Los canales de Atresmedia son los que tienen un mayor número de espectadores habituales (The Cocktail Analysis, 2018).

Así, entre los principales resultados, destaca cómo la Smart TV es ya referencia a la hora de ver contenidos. Por primera vez, el número de internautas que tienen Smart TV es superior a los que no la tienen, un 57\% frente al $49 \%$ de 2017. Además, un $18 \%$ conecta un Chromecast a su televisor $(+13 \%$ Vs. 2017), un $28 \%$ conectan el smartphone $(+21 \%$ Vs. 2017) y un $22 \%$ la tablet 
(+18\% Vs. 2017). Por su parte, el consumo de video mobile se dirige hacia la individualización y la desvinculación del hogar.

El 82\% de los usuarios de smartphone consume contenidos televisivos en este dispositivo, dedicando más de 4 horas de media a la semana y un $37 \%$ declara que incrementaría su uso si dispusieran de datos ilimitados. El consumo de contenidos en este dispositivo se da en múltiples contextos, destacando especialmente fuera del hogar ( $51 \%$ de los internautas), y en una estancia sin televisión (34\%) dentro del hogar. Todos estos datos y muchos más que podrían ser aportados a propósito de la actividad económica de consumo reflejan perfiles que, sobre todo, configuran cohortes de edad de los usuarios que se acumulan especialmente entre los quince y los 50 años, pero sobre todo entre los 20 y los 30 . Finalmente, compiten por sus usuarios las conexiones de Televisión por Protocolo de Internet (Internet Protocol Television o IPTV), aumentando apps para ver IPTV en Smart TV, o mediante codificadores, así como para ver la TDT (TDV digital Terrestre) y las Operadoras por servicio OTT (over-the-top, de libre transmisión), como Netflix, Rakuten TV, Amazon Prime Video, beIN Connect, YouTube, HBO, etc.

Gráfico 5. Reparto de porcentajes del consumo por plataformas online

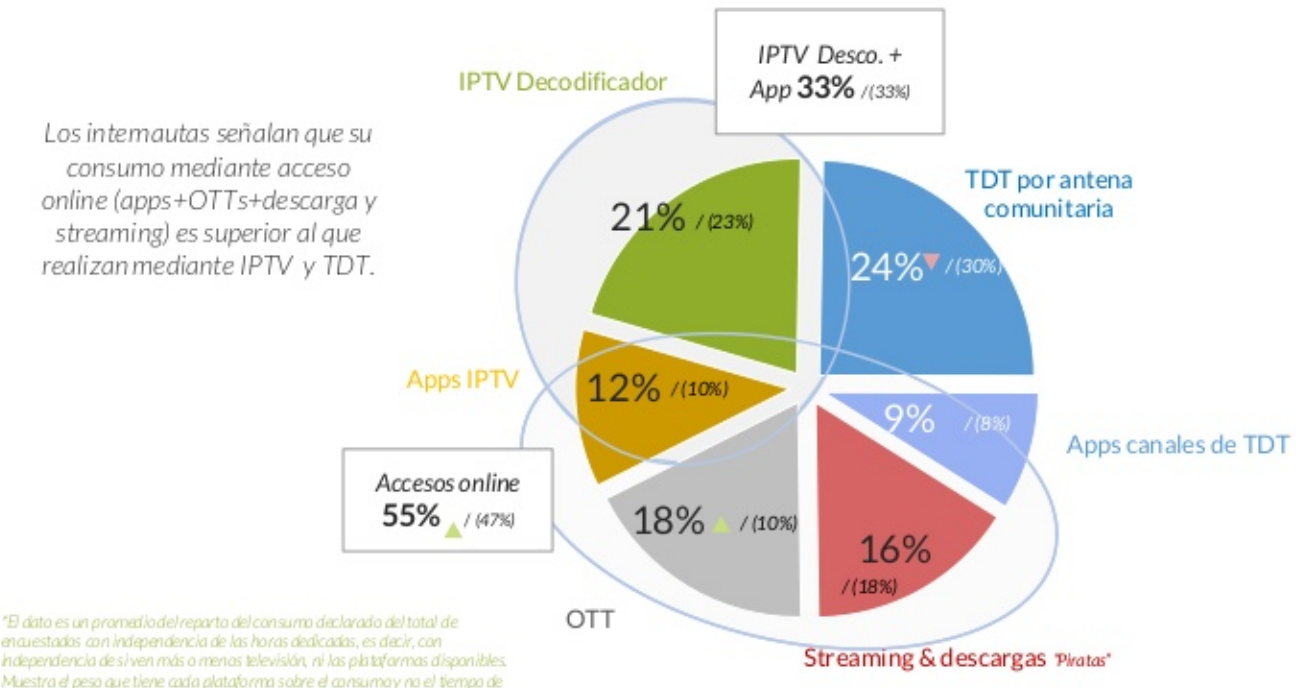

Fuente: The Cocktail Analysis (2018). 


\subsection{Verdad y manipulación frente al cambio climático}

Traer a colación el caso de cómo se ha desarrollado hasta hace poco el debate sobre el cambio climático en el ciberespacio, resulta ilustrativo del todo vale que impera cuando entran en colisión los intereses de las energéticas -que recientemente perdieron la cabeza de los rankings por rendimiento económico-, frente al poderío de las nuevas líderes, gestoras de la comunicación digital en el ciberespacio, celosas del control de las conexiones; pero, también de atizar los debates ante el riesgo del consenso científico sobre la emergencia climática causada por la emisión de Gases de Efecto Invernadero (GEI) como efecto del abuso de combustibles fósiles. Y ello, ante las previsiones científicas y el consenso sobre su diagnóstico, unido a la presión de los científicos sobre la mediación del periodismo para generar en la opinión pública tanto demandas de actuaciones políticas, como aceptación de las respuestas políticas a requerimiento de los científicos. Tal como comenta Carvalho:

Los medios de comunicación son elementos clave en la mediación de las "relaciones de definición" (Beck, 1992) entre las esferas científica, pública y política. La noción de ciencia como una "torre de marfil", exenta de la exposición y del debate públicos, es cada vez más inadecuada. Puesto que nuestra "sociedad de riesgo" (Beck, 1992) genera nuevos problemas que requieren una interpretación científica, pero que nos afectan a todos, a la ciencia se le pide que "salga a la calle" y sea la base de las decisiones políticas. Los políticos suelen esperar que los científicos proporcionen respuestas a los problemas que se debaten en los medios de comunicación y en otros escenarios públicos, y realizan toda una variedad de usos públicos de la ciencia para legitimar la acción o la inacción. El conocimiento científico también es utilizado por un gran número de actores sociales, entre los que se incluyen las empresas y los activistas, para justificar programas concretos. conforme se van estableciendo nuevos vínculos entre ciudadanos, científicos, políticos y profesionales de los medios de comunicación; el anclaje de la ciencia y la política se ha vuelto cada vez más público y la ciencia se ha visto expuesta a la crítica, la refutación y la deconstrucción (citado en Piñuel et al., 2012).

La ceremonia de la confusión fue agitada primero por el negacionismo, y después por el escepticismo instalando el discurso de las controversias climáticas desde instancias que preferían con frecuencia permanecer ocultas, y llegando posteriormente a defender posturas de optimismo tecnológico con el objeto de desactivar la contestación frente al consumo energético de combustibles fósiles. Ahora bien, según hemos expresado en Piñuel et al. (2013), la emergencia de fuentes diversas de información siempre hoy mediatizadas por los medios de comunicación de masas, se ven fuertemente sometidas a otras controversias más carentes de legitimidad porque se fraguan en redes interpersonales de interpretación (las conversaciones efímeras) que, en 
consecuencia, resultan fragmentadas y descontextualizadas, porque esas redes se sostienen sobre vínculos cada vez más vulnerables...

Conviene así sobre todo negar que las situaciones de inestabilidad social sean dependientes de la incertidumbre en circulación. Porque una cosa es considerar situaciones de inestabilidad social y otra considerar la incertidumbre. Puede haber inestabilidad social — procesos acelerados de cambios, riesgos serios para la salud de las personas y carencia de recursos elementales de comida, agua, etc., como ocurre en las guerras, o se vaticina ante las consecuencias del cambio climático- $-\mathrm{y}$, sin embargo, desaparecer toda incertidumbre porque un discurso social compartido se torna vigente y hegemónico. Así ocurre cuando los fascismos o los fundamentalismos triunfan acrecentando el número de sus seguidores, dispuestos a arriesgar su vida en pos de una causa...

Mientras que, al contrario, puede haber estabilidad social — sólo se aceleran cambios menores, cualquier atisbo de revolución o de cambio trascendental deja de ser vislumbrado, y tanto la salud como la provisión de recursos estar aseguradas, como ocurre en nuestras sociedades del primer mundo- $\mathrm{y}$, sin embargo, desaparecer toda certidumbre porque no hay un discurso social compartido vigente y hegemónico, sino varios en conflicto, cada cual cree tener el suyo, y se busca la seguridad y la confianza sobre el capital cognitivo disponible llevándolas al terreno de los afectos personales y de las redes de discusión y controversia que brindan las relaciones personales, cada vez más efímeras y virtuales...

Frente a esta vulnerabilidad e inconsistencia existencial, las relaciones efímeras de la cotidianeidad — sean físicas o virtuales-, también acuden al aval de las agendas públicas y mediáticas que los políticos y decisores, como los periodistas y empresarios mediáticos, que, a su vez, mantienen por el aval de los expertos científico-técnicos, gracias a cuya legitimación prestada, las actuaciones políticas y los discursos mediáticos se tornan en hegemónicos. Este círculo vicioso de legitimaciones buscadas permite explicar cómo la construcción social de la agenda del acontecer, reproducida por el discurso del periodismo, lleva a las audiencias a confiar en aquellos discursos que sirven para afrontar las quiebras del acontecer de esa agenda, primando, en unos casos, lo que se dice de lo que ocurre (la verdad/falsedad); en otros, lo que conviene hacer tras lo que se dice (lo bueno/malo); y, finalmente, en otros casos, cómo se dice lo que se hace (lo atractivo/repulsivo). En definitiva, la construcción social de la agenda del acontecer, reproducida por los discursos del ciberespacio, constituye el dominio de existencia histórico y el marco epistémico de su conocimiento, ético de su actuación y ecológico de su sostenibilidad. Se impone pues reclamar para la ciudadanía y su inclusión en el ciberespacio, la democratización de la comunicación. 
60

\subsection{Ciudadanía e inclusión desde lo digital: la democratización de la comunicación}

¿Qué debería ser entendido por democratización de la comunicación al tomar en consideración el ciberespacio? Aparentemente la inmediatez en las conexiones, la libertad de expresión, la interactividad e independencia de las que puede disfrutar el usuario en el ciberespacio tan sólo sirviéndose de la disponibilidad de aparatos para las conexiones y de su competencia para el manejo de estos, hacen de esta época el paraíso de la inclusión y de la participación ciudadanas. Aparentemente. Lo que ocurre, sin embargo, es que hoy el tejido social del encuentro entre medios - capitalizando los discursos-, y audiencias - que, en lugar de escuchar y ver, ahora pueden reaccionar hablando (mejor gorjeando [Twitter]) todos a la vez-, se urde por medio de la conversación virtual gracias a la multitarea facilitada mediante el manejo simultáneo de diversos dispositivos y pantallas. Pero, sobre todo, gracias a las redes sociales que constituyen hoy una lonja virtual donde se exhibe el valor simbólico de la propia identidad, siempre en construcción.

Y en este empeño, la práctica social de circular por el ciberespacio le brinda al sujeto recursos y habilidades de socialización, abriéndoles ventanas a la percepción de la realidad social frente a la cual, el contacto, la red de amigos y el reconocimiento del sí mismo se torna en asidero vital de seguridad y permanencia. Podemos citar como antecedentes, en lo que respecta a los procesos de percepción social del acontecer y sus quiebras (noticias), estudios realizados en torno a la incertidumbre por Ulrich Beck (1998 y 2002); Lozano Ascencio (2002 y 2003); Gil Calvo (2003) y diversos trabajos realizados en torno a la construcción social de la realidad, por Berger y Luckmann (1976); Gergen y Warhus (2003), etc.

Y por lo que respecta al contexto del nuevo tejido social urdido por el uso que tanto los medios como las audiencias hacen de las denominadas redes sociales, podemos citar a Castells (2001). El propio Manuel Castells, en la entrevista publicada el 4 de agosto de 2013 en el Blog de Sociología y actualidad denominado Sociólogos, afirmaba que «[...]la sociabilidad real se da hoy en Internet» (Castells, 2013).

Nos planteamos así que medios y audiencias usan las redes sociales creando hoy día un nuevo lugar social de encuentro caracterizado por su ubicación virtual en Internet, donde los medios se aproximan personalmente a sus audiencias y donde las audiencias, hasta ahora dispersas, se reúnen para estar en contacto o estar atentos y como amigos o seguidores (followers) conversar. Unos y otros se presentan, se siguen y persiguen, se intercambian opiniones, imágenes, vídeos, y tejen sus relaciones sin los riesgos del contacto próximo y 
precaviendo la intimidad. Así, ya es casi viejo el que los medios de comunicación se hagan presentes en las redes sociales (Facebook, Twiter, YouTube...).

Por su parte, (Cfr. Piñuel et al., 2013) las audiencias se sirven de las redes sociales como de una lonja virtual donde se subasta el valor simbólico de la propia identidad que, siempre en continuo proceso de construcción y mejora, acude primordialmente al encuentro de sus iguales para afianzarse en la relación, por una parte, y compartir el conocimiento del entorno, por otra, siendo los discursos mediáticos de las plataformas virtuales que se están viendo o que se han visto, objeto de comentarios en las conversaciones en el ciberespacio casi tan importantes como el resto de contenidos sobre intercambios de fotos y expresiones, o sobre las cosas que se están realizando mientras se hacen las conexiones virtuales. Una ilustración curiosa del interés por el que según diferentes frecuencias los usuarios de redes sociales abordan determinadas referencias cuando conversan en ellas, se muestra en los resultados a una pregunta de la encuesta que The Cocktail Analysis realizó en 2013, y que se ven en el Gráfico 6:

\section{Gráfico 6. Tipos de contenidos sobre los que se realizan comentarios en plataformas sociales}

\section{Tipos de contenidos}

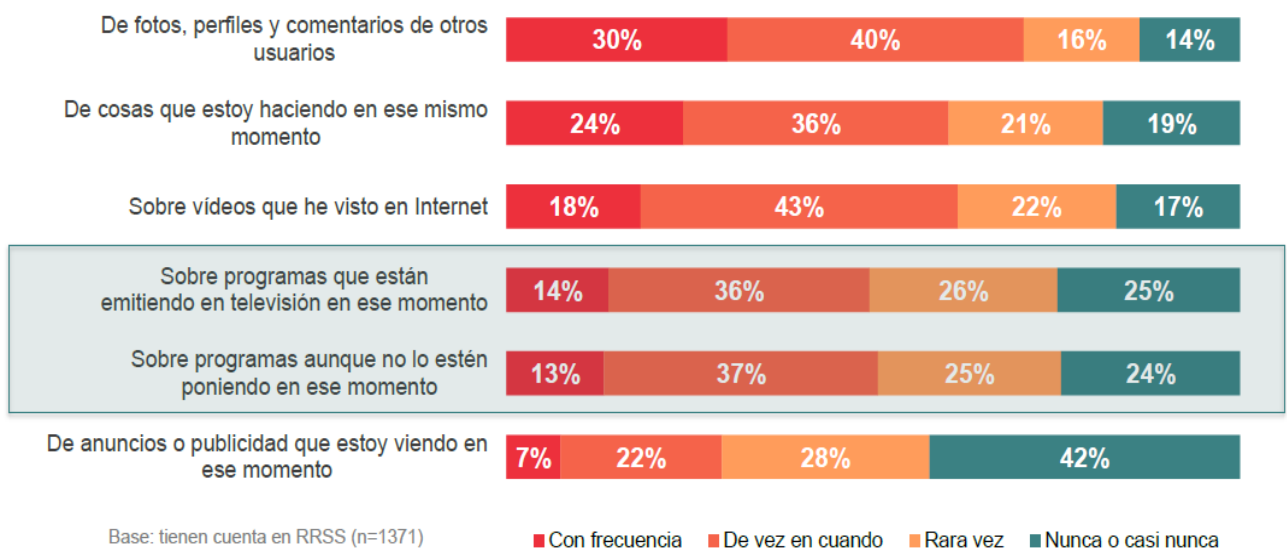

Fuente: The Cocktail Analysis (2013).

Tras la exposición de tales datos, aparece un perfil de ciudadano que, por su consumo audiovisual, y de manera primordial en la juventud, se realiza utilizando simultáneamente diversos dispositivos convergiendo con las diversas pantallas digitales, y que su conexión, preferiblemente a la carta, y sin seguir 
parrillas de programación temporalmente ubicadas, se articula siguiendo el curso de conversaciones virtuales cuya sinergia secuencial se teje en las redes sociales. Ello puede hacer comprender fácilmente el interés de los medios de comunicación por intervenir en las redes sociales al encuentro de sus audiencias, compitiendo entre sí por ganar la confianza de sus seguidores (followers), y, sobre todo, incentivando el crecimiento del tejido de las conexiones, de la malla virtual, de las redes sociales, y de los contenidos cuya espectacularidad mejor pueda alimentar las conversaciones como los dispositivos más eficaces para incrementar la sociabilidad. ¿Y qué pasa con la comunicación política, gubernamental y lo que podríamos cuestionar como ciberpolítica?

\subsection{Comunicación política, gubernamental y ciberpolítica}

Las redes sociales se han tornado esenciales para los movimientos sociales actuales y el activismo político (Castells, 2013) y según investigaciones empíricas (cfr. Cortez Vásquez, 2011), están ocupando, por ello, un lugar central en el activismo político hasta el punto de que este hecho supone la aparición de los denominados nuevos movimientos sociales. La investigación de Judith Cortéz Vásquez (2011) titulada Nuevos movimientos sociales y uso de las nuevas tecnologías. Estudio de casos abordó el estudio de dos célebres movimientos sociales surgidos por masivas convocatorias en redes sociales. Uno, a través de Facebook, en Colombia - Un millón de voces contra las FARC - con repercusiones importantes en Europa y América Latina, y otro en Italia - Beppe Grillo di Napoli-, a través de la plataforma de Meetup, que logró convertirse en un movimiento social político denominado Movimento 5 stelle.

Se aplicaron las técnicas cualitativas de entrevista y cuantitativas de encuesta para conseguir los datos de las expectativas y aspiraciones de los sujetos movilizados a través de las redes sociales, mientras que los datos para los análisis de los discursos online y offline se obtuvieron de la aplicación de las técnicas del análisis de contenido. Abordando el fenómeno de los movimientos ciudadanos dentro y fuera de las redes sociales, se comprobó hasta qué punto las redes sociales fueron decisivas como instrumentos de convocatoria y movilización social; mientras que los procesos de participación ciudadana y compromiso necesitaron de las resonancias mediáticas tanto dentro como fuera de las redes, pero especialmente fuera, para ser mantenidos alimentando la implicación de sus militantes. Su rasgo diferencial fue el uso intensivo de la tecnología de redes sociales para desafiar o alterar las maneras dominantes, esperadas o aceptadas de hacer sociedad, cultura y política. 
Casero-Ripollés (2015), concluye su trabajo etnográfico sobre la actividad de movimientos sociales y su estrategia comunicativa en las redes sociales, diciendo que:

Los resultados obtenidos permiten afirmar que las redes sociales juegan un papel fundamental en las dinámicas de los activistas políticos en España. Éstos incorporan a sus estrategias y practicas comunicativas la automediación, la monitorización y el establecimiento inverso de la agenda. Así, la web 2.0 ofrece numerosas potencialidades, en términos de empoderamiento, para el activismo político, pero, a la vez, también plantea límites a su acción.

La automediación se configura como un aspecto altamente valorado por los activistas y como un elemento clave de sus estrategias comunicativas ya que ofrece grandes posibilidades de ejercer el contrapoder. Pese a que las redes sociales abren la opción de elaborar contenidos a cualquier ciudadano, los activistas políticos españoles consideran que la clave reside más en la distribución masiva de los mensajes que en su producción, expresando, así, una visión elitista de este proceso. Esta idea busca combatir los problemas derivados del exceso de producción de contenidos por parte del activismo que introduce ruido y dispersión en la automedicación y la debilita. Los resultados revelan la ausencia de visión crítica de los activistas políticos españoles respecto a la automediación, de la cual sólo se perciben las ventajas, adoptando un punto de vista ciberutópico y soslayando las limitaciones. En cuanto a las prácticas, se detectan dos grandes modalidades de automediación en el contexto español: aquella basada en contenidos ajenos, centrada en la difusión, y aquella basada en contenidos propios, enfocada hacia la producción.

La monitorización también es percibida como un elemento importante de las estrategias comunicativas por parte de los activistas políticos españoles ya que les permite cuestionar el orden establecido y exigir medidas correctoras de regeneración democrática. Sin embargo, éstos les otorgan una menor relevancia respecto a los otros dos procesos analizados. Esto genera una paradoja ya que las iniciativas de escrutinio de los centros de poder puestas en marcha en España han proliferado desde 2011. Se demuestra, así, la existencia de una disonancia entre las prácticas y las estrategias comunicativas de los activistas. Dos motivos explican esta situación: la confusión y la inexactitud a la hora de identificar el significado y alcance de la monitorización detectada entre los activistas españoles, por un lado, y las objeciones respecto a su falta de utilidad si no logra conectarse con la movilización, por otro.

Finalmente, los resultados revelan que el establecimiento inverso de la agenda es la estrategia comunicativa preferida por parte de los activistas políticos españoles gracias a su capacidad para situar sus temas y marcos discursivos en los medios convencionales y en el debate público. Su aplicación se basa en sofisticadas campañas digitales para generar temas del momento a través de hashtags que implican la coordinación y sincronización de numerosas personas, respondiendo al concepto de inteligencias 
múltiples (Lévy, 2007). Su objetivo es captar la atención de los medios convencionales y lograr que éstos lo integren en su agenda, dándole visibilidad social. Se emplean, así, las redes sociales para influir en la cobertura mediática. Por ello, supone el reconocimiento por parte del activismo del papel central de los medios en la construcción de la agenda publica, lejos de cuestionarlo. [...] Los resultados indican que los activistas son conscientes de la gran dificultad que entraña esta modalidad de construcción inversa de la agenda. Una de las principales, que limita su potencial, es el empleo intensivo de campañas digitales, que genera problemas de saturación, descoordinación y de falta de solidaridad dentro del propio movimiento activista.

Estos tres procesos demuestran que las redes sociales introducen novedades en las prácticas y las estrategias comunicativas de los activistas políticos. Nuevas dinámicas que, pese a contar con limitaciones que pueden condicionar su alcance, ofrecen a los movimientos sociales nuevas oportunidades para influir en la estructura y los debates de la esfera pública con el objetivo de transformar la política y la sociedad (Casero-Ripollés, 2015: 547-48).

Quedan tres aspectos a ser puestos en relación con las decisiones del activismo político que acaba de ser objeto de reflexión y comentario. Se trata del derecho al acceso de la información, la exigencia de transparencia en la información gubernamental, el uso de las redes y comunidades sociodigitales en los procesos electorales y las alternativas de la comunicación comunitaria en los escenarios del ciberespacio.

\subsection{Derecho al acceso de la información}

Si se entiende el acceso a la información como el acceso a las fuentes, que es tanto como decir el acceso a los hechos, a los acontecimientos, a sus protagonistas, entonces resulta que la cuestión remite más al derecho a buscar información que al derecho a recibirla. Y esto tiene su réplica consiguiente en la garantía de transparencia en el curso del acontecer planificado, en los procesos de gobernanza. Pero si se entiende el acceso a la información como confianza de estar informado, a no ser excluido o impedido de recibirla caso de necesitarla, entonces su réplica consiguiente apunta a ser reconocido miembro de la comunidad de intereses, al derecho a recibir la información o, dicho de otra manera, al derecho a la participación ciudadana.

Respecto al primer caso, en el portal de la transparencia en España se puede leer:

Todas las personas tienen derecho a acceder a la información pública, en los términos previstos en el artículo 105.b) de la Constitución Española, desarrollados por la Ley de Transparencia. La información pública es el conjunto de los contenidos o los documentos, cualquiera que sea su formato o soporte, que obren en poder de alguno de los sujetos incluidos 
en el ámbito de aplicación del título I de la Ley 19/2013 de Transparencia de 9 de diciembre, Acceso a la Información y Buen Gobierno y que hayan sido elaborados o adquiridos en el ejercicio de sus funciones (Gobierno de España, s. f.).

En este mismo portal se incluye luego una guía paran solicitar información, hacer el seguimiento de las solicitudes cursadas, proporcionar datos de la actividad ocasionada por las solicitudes tramitadas, y en general sobre los procedimientos que se desarrollan a este propósito dando cumplimiento a este derecho.

Respecto al segundo caso, si se entiende el acceso a la información como confianza de estar informado, a no ser excluido o impedido de recibirla caso de necesitarla, se trata de uno de los derechos fundamentales recogidos en la mayoría de las constituciones democráticas. Y concretamente en el Artículo 19 de la Declaración Universal de los Derechos Humanos. aprobada por la Asamblea General de las Naciones Unidas el 10 de diciembre de 1948, se dice:

Todo individuo tiene derecho a la libertad de opinión y de expresión; este derecho incluye el de no ser molestado a causa de sus opiniones, el de investigar y recibir informaciones y opiniones, y el de difundirlas, sin limitación de fronteras, por cualquier medio de expresión (Declaración Universal de los Derechos Humanos, 1948).

En cualquiera de los dos casos, la cuestión se acaba centrando siempre en cómo exigir la transparencia que atañe a la información pública, es decir, a la información cuya carencia afecta a los derechos fundamentales del ciudadano.

\subsection{Modos de exigir la transparencia en la información gubernamental}

Son muy frecuentes las ocasiones en las que, por costumbre según los países, o por diferencias en la tradición, se usan indistintamente los términos de información pública e información gubernamental, aunque no debiera ocurrir tal cosa. En España, la Ley 19/2013, denominada comúnmente como Ley de transparencia 5 , expresa, en su primer artículo, que para regular el concepto de comunicación / información pública,

Esta Ley tiene por objeto ampliar y reforzar la transparencia de la actividad pública, regular y garantizar el derecho de acceso a la información relativa a aquella actividad y establecer las obligaciones de buen gobierno que deben cumplir los responsables públicos asil como las consecuencias derivadas de su incumplimiento (Ley 19/2013).

\footnotetext{
${ }^{5}$ Ley 19/2013, de 9 de diciembre, de transparencia, acceso a la información pública y buen gobierno.
} 
Y en su artículo 13 la información pública se define de nuevo con el siguiente tenor:

Se entiende por información pública los contenidos o documentos, cualquiera que sea su formato o soporte, que obren en poder de alguno de los sujetos incluidos en el ámbito de aplicación de este título y que hayan sido elaborados o adquiridos en el ejercicio de sus funciones (Ley 19/2013).

Según comenta Ibáñez (2014: 185), con el acceso a esta gran amplitud de datos e informaciones, por parte de cualquier ciudadano, se pretende incrementar y reforzar la transparencia en la actividad pública al tiempo que «[...] reconoce y garantiza el acceso a la información — regulado como un derecho de amplio ámbito subjetivo y objetivo-[...]». Y, continúa Ibáñez, «Introduce una serie de obligaciones que bajo el término "publicidad activa" obliga al Estado y las Administraciones Públicas a poner a disposición de la ciudadanía, sin solicitud previa alguna, información cuyo conocimiento se considere de interés». No obstante, luego han sido protocolizadas las solicitudes de información cuando se ha creado el Portal de la Transparencia al objeto de facilitar una mayor agilización. Como se ha dicho antes, este mismo portal incluye una guía para solicitar información, hacer el seguimiento de las solicitudes cursadas, proporcionar datos de la actividad ocasionada por las solicitudes tramitadas, y en general sobre los procedimientos que se desarrollan a este propósito dando cumplimiento a este derecho frente a la Administración. Concretamente el ámbito informativo en que se aplica esta Ley viene fijado en los artículos 6, 7 y 8 ; y abarca los siguientes tipos de información: Información institucional, organizativa y de planificación; Información de relevancia jurídica; Información económica, presupuestaria y estadística.

De cualquier forma, Ibáñez (2014) añade que esta ley está impregnada de un marcado tinte político, pues parece que únicamente se pretende poner en marcha ciertas medidas para la regeneración democrática de toda la Administración, y más bien parece enfocada únicamente a regular la gestión de los datos que se encuentran en poder de la Administración. Hasta el punto es así, que olvida referirse a la Ley 29/2005, de Publicidad y Comunicación Institucional, en materia de campañas institucionales de publicidad y de comunicación, que en su disposición adicional séptima dice que: «El Gobierno aprobará un plan formativo en el ámbito de la transparencia dirigido a los funcionarios y personal de la Administración General del Estado, acompañado, a su vez, de una campaña informativa dirigida a los ciudadanos»; término éste -el de campaña informativa-, carente del rigor que cabe esperar en un texto legal ya que, según la Ley 29/2005, el término «campaña informativa» en la Administración no existe. El término 
campaña suele, sin embargo, encontrarse centrado más bien al tomar en cuenta la vulnerabilidad reciente que aqueja a los procesos electorales.

\subsection{Usos de las redes sociodigitales en los procesos electorales}

Aprovechando la explotación de las emociones mediante maniobras automatizadas con ayuda de la Inteligencia Artificial (AI) y de enjambres de robots, millones de usuarios del ciberespacio recibieron incontables noticias falsas en las redes sociales como Facebook y otras con ocasión de campañas electorales, como la del Donald Trump, y de referéndums como el del Brexit. Con ello, una empresa llamada Cambridge Analytica activó lo que podríamos llamar una epidemia de infoxicación que saca provecho de los macrodatos que, procedentes de las huellas que los internautas dejan en el ciberespacio, configuran las personalidades de los votantes individuales para manipular después la opinión pública. A juicio de Berit Anderson, directora general de Scout.ai ${ }^{6}$ y de Brett Horvath, jefe de su departamento de estrategia y desarrollo, muchas de estas tecnologías se han utilizado por separado anteriormente con cierto efecto, pero juntas forman una máquina de manipulación de votantes casi impenetrable que se está convirtiendo rápidamente en el nuevo factor decisivo en las elecciones alrededor del mundo.

Hoy día, Cambridge Analytica es una empresa cancelada que combinaba la minería y el análisis de datos con la comunicación estratégica para procesos electorales. La empresa fue creada en 2013 como una rama de la casa matriz Strategic Communication Laboratories, para participar en la política estadounidense. Brittany Kaiser, que según comunicaba el periódico online español elDiario.es (Escribano, 2019), pasó de ser becaria de la campaña electoral de Barack Obama a trabajar para Cambridge Analytica en favor del Brexit y la candidatura de Trump, ha comenzado recientemente a desvelar los secretos de esta compañía, y en el documental El gran hackeo (Karim Amer y Jehane Noujaim, 2019) distribuido por Netflix cuenta ella misma lo que define como un efecto boomerang: «[...] se recogen tus datos y vuelven convertidos en forma de discurso político, cuando no de bulo». Y acaba pidiendo que las psicografías de los votantes tengan la misma consideración que las armas. Pero a mi juicio lo más grave no es tanto el abuso electoralista de la minería de datos, sino la persistencia de sus efectos debido a las burbujas informativas que se han ido generando con la distribución masiva de noticias y falsas noticias que reciben los individuos con perfiles psicológicos similares en comunidades virtuales a través de sus redes sociales en el ciberespacio. ¿Hay alternativas?

${ }^{6}$ Un portal centrado en la prospectiva sobre Inteligencia Artificial. 


\subsection{Comunicación comunitaria, alternativa y popular en escenarios de posverdad}

Llegados a este punto de las reflexiones expuestas, sirva como conclusión decir que las nociones correspondientes a los términos de comunicación comunitaria, alternativa y popular pierden, al enunciarlos en escenarios de posverdad ubicados en el dominio del ciberespacio, su significado original de cuando surgieron en los años 60 y 70 del siglo pasado. Por ejemplo, en virtud del uso y abuso de las redes sociales de los consumidores de conexiones a través de internet, por una parte; así como, por otra parte, por el uso y abuso de la minería de datos monetarizados por los operadores de las conexiones brindándoles las psicografías de los consumidores a terceros, se da como efecto el surgimiento de comunidades virtuales de cuya comunicación se destila un sentido de resistencia en la conciencia de su identidad. Y es este sentido de resistencia el que constituía el acicate para el surgimiento de comunidades y de las comunicaciones comunitarias, y que hoy constituye el cebo luego aprovechado por las maniobras de explotación emocional llevada a cabo por la Inteligencia Artificial en la producción robótica de discursos con distribución personalizada entre los usuarios de las redes sociales.

Así, para Morales Navarro y Abad Márquez (1997) los llamados grupos sociales, a la hora de explicar el surgimiento de la comunicación comunitaria en su resistencia frente a los discursos hegemónicos de los media de los años $70 \mathrm{y}$ 80, podían ser definidos como «[...] el conjunto de personas que comparten valores, actitudes y roles interrelacionados, objetivos comunes, poseen conciencia de unidad y una existencia reconocida como tal por los demás» (Morales Navarro y Abad Márquez, 1997: s. p.). Una comunicación alternativa podía surgir entonces como el canal por el cual una comunidad luchadora compuesta por sujetos sociales llevaba a cabo sus objetivos, convirtiéndolo en el medio por donde aspiraban a llegar a la gente. 0 , dicho de otra manera, inconformes con las imposiciones de los grupos dominantes en el acceso y uso de los medios masivos convencionales, tomaban esa alternativa para comunicar. El propósito era organizarse para buscar la información y poder comunicar ellos mismos, y así sentirse sujetos trascendentales por reivindicar el ejercicio de sus derechos. Entonces la comunicación alternativa reclamaba ser el instrumento idóneo para la lucha popular contra el poder. La alternativa entonces era planteada frente al acceso de unidireccionalidad obligada en la circulación de informaciones, lo cual ha sido transformado en los escenarios del ciberespacio.

Dice Biagini (2013: 49) que lo que se denomina alternativo es aquello que es considerado opuesto a su contrario citando como ejemplo los pares de términos: Emergente-Hegemónico; Inclusivo-Excluyente, Popular-Elitista. 
Nuestro planteamiento, entonces sería: ¿Y cuál es lo emergente y cuál lo hegemónico en el ciberespacio? ¿Cuál lo inclusivo y cuál lo excluyente? ¿Y cuál es lo popular y cuál lo elitista? En relación con la comunicación este paralelo evidencia comportamientos sociales e ideologías que, aspirando a una propuesta de cambio social en la comunicación (Barranquero y Sáez-Baeza, 2012), procure ser alternativa primero a la hegemonía impuesta en la circulación de señales, donde siguen siendo dueños las compañías operadoras. Segundo, en la hegemonía establecida para el procesamiento de los mensajes, de los cuales se retienen sus huellas y registros por usuario, catalogando sus diferencias en torno a la oposición entre popular y elitista. Tercero, ser alternativa a la minería de datos usando los algoritmos de la AI procesando los textos sin contexto y replicándolos mediante automatismos robóticos; y cuarto, ser alternativa a las comunidades virtuales de cuyos discursos en circulación para la construcción de la identidad, se retiene la exclusión de los extraños a la comunidad y la inclusión emocional y ciega, de solo los próximos. En definitiva, la comunicación comunitaria, alternativa y popular en escenarios de posverdad debiera ser diseñada a partir de la crítica y posterior alejamiento del ciberespacio, cuya toxicidad aumenta con el incremento desbordado de la frecuentación y consumo acrítico de las redes sociales.

\section{Referencias bibliográficas}

BARRANQUERO, A. y SÁEZ-BAEZA, C. (2012). Teoría crítica de la comunicación alternativa para el cambio social: el legado de Paulo Freire y Antonio Gramsci en el diálogo norte-sur. Razón Y Palabra, 16 (1_80), 40-52. Recuperado a partir de

\section{http://www.revistarazonypalabra.org/index.php/ryp/article/view/ 457}

BAUDRILLARD, J. (1984). Cultura y simulacro. Barcelona: Kairós.

BECK, U. (2003). Comunicación social y riesgos globales. Congreso

Iberoamericano de Comunicación y Luces en el laberinto audiovisual. Educomunicación en un mundo global. Huelva.

BECK, U. (1998). World Risk Society. Cambridge: Polity Press.

BECK, U. (1992). Risk Society: Towards a New Modernity. London: SaGe.

BERGER, P. L. y LUCKMANN, T. (1972). La construcción social de la realidad. Buenos Aires: Amorrortu.

BIAGINI, H. (2013). El pensamiento alternativo y su génesis. Centro de Investigaciones sobre América Latina y el Caribe. Cuadernos Americanos Nueva Época, 146 (México, 2013/4), pp. 49-66. 
70

BlanCo-Herrero, D. y ARCila-CALDERón, C. (2019). Deontología y noticias falsas: estudio de las percepciones de periodistas españoles. El profesional de la información, 28, 3, e280308.

https: / / doi.org/10.3145/epi.2019.may.08

CASERO-RIPOLLÉS, A. (2015). Estrategias y prácticas comunicativas del activismo político en las redes sociales en España. Historia y Comunicación Social, 20, 2, 535-550.

CASTELLS, M. (2013, 4 de agosto). Entrevista a Manuel Castells: La sociabilidad real se da hoy en Internet. S Sociólogos. Recuperado a partir de http: / / ssociologos.com/2013/08/04/manuel-castells-lasociabilidad-real-se-da-hoy-en-internet

CASTELlS, M. (2001). La Galaxia Internet. Reflexiones sobre Internet, empresa y sociedad. Barcelona: Plaza y Janés (Areté).

CASTElls, M. (2013). Comunicación y poder Sociología y política. México: Siglo XXI Editores.

CORTÉZ VASQUEZ, J. (2011). Nuevos movimientos sociales y usos de las nuevas tecnologías: estudio de casos. Tesis doctoral de la Facultad de Ciencias de la Información. Universidad Complutense de Madrid. Doctorado con mención europea.

CosTA, P.T., Jr. y McCrae, R.R. (1994). Revised NEO Personality Inventory (NEOPI-R) and NEO Five-Factor Inventory (NEO-FFI) manual. Odessa, FL: Psychological Assessment Resources.

DECLARACIÓN DE LOS DERECHOS HuMANOS (1948). Organización de las Naciones Unidas. Recuperado de https://www.un.org/es/universal-declarationhuman-rights

DigMAN, J.M. (1990). Personality structure: Emergence of the five-factor model. Annual Review of Psychology, 41, 417-440.

ESCRIBANO, M. (2019, 10 de agosto). De becaria de Obama a desvelar los secretos de Cambridge Analytica: ¿quién es Brittany Kaiser? elDiario.es. Recuperado a partir de https://www.eldiario.es/tecnologia/obamacambridge-analytica-brittany-kaiser_1_1480274.html

GERGEN, K. y WARHUS, L. (2003). La terapia como una construcción social: dimensiones, deliberaciones y divergencias. Revista Venezolana de Psicología Clínica Comunitaria, 3, 3-44.

GIL CALVO, E. (2003). El miedo es el mensaje: riesgo, incertidumbre y medios de comunicación. Madrid: Alianza editorial.

GOBIERNO DE ESPAÑA (s.f.). Portal de la transparencia. Recuperado a partir de https://transparencia.gob.es/transparencia/transparencia_Home/in dex/Derecho-de-acceso-a-la-informacion-publica.html 
GoldBerg, L. R. (1993). The Structure of Phenotypic Personality Traits. The Sixth European Conference on Personality, European Association of Personality Psychology on June 16-19, in Groningen (The Netherlands). Recuperado a partir de http://psych.colorado.edu/ carey/courses/psyc5112/readings/psn structure_goldberg.pdf

IBÁÑEZ, A. (2014). Comunicación, Administraciones Públicas y gestión de crisis y emergencias. Tesis doctoral de la Facultad de Ciencias de la Información. Universidad Complutense de Madrid.

LEY 19/2013, de 9 de diciembre, de transparencia, acceso a la información pública y buen gobierno. Boletín Oficial del Estado, 295, de 10 de diciembre de 2013. Recuperado de https://www.boe.es/buscar/act.php?id=BOEA-2013-12887

LEY 29/2005, de 29 de diciembre, de Publicidad y Comunicación Institucional. Boletín Oficial del Estado, 312, de 30 de diciembre de 2005, 42902 a 42905. Recuperado de https://www.boe.es/buscar/doc.php?id=BOE-A-2005$\mathbf{2 1 5 2 4}$

LOZANO ASCENCIO, C. (2002). La cultura del riesgo global a las catástrofes. VII Congreso Iberoamericano de Comunicación (IBERCOM). Maia, Oporto, Portugal.

MATURANA R. H. y VARELA G., F. $(1973,1996)$. El árbol del conocimiento. Las bases biológicas del entendimiento humano, Prefacio de Rolf Behncke C. Lumen / ED. L Universitaria.

MAYORAL, J. y EDO, C. (2014). Evolución de la producción audiovisual en cinco cibermedios españoles. Journal of Communication, 9, pp. 233-262.

MORALES NAVARRO, J. y ABAD MÁRQUEZ, L. V. (1997). Introducción a la Sociología. Madrid: Tecnos. ISBN 10: 8430915877 / ISBN 13: 9788430915873.

NYHAN, B. y REIFLER, J. (2010). When corrections fail: The persistence of political misperceptions. Political Behaviour, 32, 2, pp. 303-330. Recuperado en https: / /link.springer.com/article/10.1007/s11109010-9112-2

PARISER, E. (2017). El filtro burbuja: Cómo la web decide lo que leemos y lo que pensamos. Madrid: Taurus.

PiÑUEL, J.L. y ARRojo BALIÑA, M. J. (2014). Contenidos digitales y multipantalla. (Coods.). Cuadernos Artesanos de Comunicación, 95. La Laguna (Tenerife): Latina.

PiñUEL, J. L., GAitán, J. A. y LoZANo, C. (2013). Confiar en la prensa o no. Un método para el estudio de la construcción mediática de la realidad. Salamanca: Comunicación Social Ediciones y Publicaciones. 
Piñuel-Raigada, J.L.; Teso-Alonso, G.; Painter, J.; CARvalho, A.; Pardo-Buendía, M. y LERA-ST.-CLAIR, A. (2012), Comunicación, controversias e incertidumbres frente al consenso científico acerca del Cambio Climático, disponible en http://www.revistalatinacs.org/067/cuadernos/artesanos.htmI\#30

PIÑUEL, J. L. y LOZANO ASCENCIO, C. (2006): Ensayo General sobre la Comunicación. Barcelona: Paidós /Papeles de Comunicación.

PIÑUEL, J.L. y GAITÁN, J.A. (1995). Metodología General. Conocimiento científico e investigación en la Comunicación Social. Madrid: Ed. Síntesis.

PIÑUEL, J.L. (1989): La Expresión. Una introducción a la Filosofía de la Comunicación. Madrid: Ed. Visor.

PORTER, E. (2017). Facts matter, and people care: An empirical perspective. En POWERS, S. y KounALAKIS, M. (Eds.). Can public democracy survive the internet? Bots, echo chambers, and disinformation. Washington: U.S. Advisory Commission on Public Diplomacy (Department of State), pp. 5159. Recuperado a partir de https: / / www.hsdl.org/ ?abstract\&did $=\mathbf{8 0 0 8 7 3}$

QUINTAS-FroufE, N. y GonZALEZ-NEIRA, A. (2014). Audiencias activas: Participación de la audiencia social en la televisión. Comunicar, 43, pp. 83-90. RAMONET, I. (2002). Propagandas silenciosas. La Habana: Instituto del Libro. RoDRíGUEZ-FERRÁNDIZ, R. (2019). Posverdad y fake news en comunicación política: breve genealogía. El profesional de la información, 28, 3, e280314.

RUSSELL, M.T. y KAROL, D. (1994). Fifth Edition administrator's manual. Champaign, IL: Institute for Personality \& Ability Testing.

TUPES, E.C. y CHRISTAL, R.E. (1950). Recurrent Personality Factors Based on Trait Ratings. Technical Report ASD-TR-61-97, Lackland Air Force.

The CockTAIL AnAlysis (2018). Informe Anual Televidente Now! (XI Oleada, 2018). Recuperado a partir de https: / /tcanalysis.com/insights/presentamos-los-resultados-de-laxi-edicion-de-televidente

THE COCKTAIL ANALYSIS (2013). Observatorio de redes sociales. (V Oleada, 2013). Recuperado a partir de http://bit.ly/YZFWP8, 25-05-2013

UfARTE-Ruiz, M.-J., PERAlTA-GARcíA, L. y MurCiA-VERdú, F.-J. (2018). Fact checking: un nuevo desafío del periodismo. El profesional de la información, 27, 4, pp. 733-741.

VAN DiJK, T. (2005). Las estructuras y funciones del discurso. México: Siglo XXI, 1980. (14a edición actualizada). 